\title{
Monitoring of Ground Movements Due to Mine Water Rise Using Satellite-Based Radar Interferometry-A Comprehensive Case Study for Low Movement Rates in the German Mining Area Lugau/Oelsnitz
}

\author{
André John
}

check for updates

Citation: John, A. Monitoring of Ground Movements Due to Mine Water Rise Using Satellite-Based Radar Interferometry-A Comprehensive Case Study for Low Movement Rates in the German Mining Area Lugau/Oelsnitz. Mining 2021, 1, 35-58. https://doi.org/ 10.3390/mining1010004

Received: 5 February 2021

Accepted: 10 March 2021

Published: 17 March 2021

Publisher's Note: MDPI stays neutral with regard to jurisdictional claims in published maps and institutional affiliations.

Copyright: (C) 2021 by the author. Licensee MDPI, Basel, Switzerland. This article is an open access article distributed under the terms and conditions of the Creative Commons Attribution (CC BY) license (https:// creativecommons.org/licenses/by/ $4.0 /)$.
TU Bergakademie Freiberg, Institute for Mine Surveying and Geodesy, Fuchsmuehlenweg 9 B, 09599 Freiberg, Germany; andre.john@mabb.tu-freiberg.de

\begin{abstract}
In terms of its history and complexity, the Lugau/Oelsnitz mining area is a representative example of many hard coal fields in Europe. The special characteristic, however, is the low water inflow and the associated long flooding process with corresponding low and long-ongoing ground movements. In order to ensure the long-term monitoring of ground movements in the future, an adapted and cost-effective concept based on modern methods should be implemented. The today widely used radar interferometry, is well established as a method but the results offer many possibilities for interpretation, which one should be aware of in order to derive reliable information. Presented are the results of a complex interferometric evaluation, based on Sentinel-1 data from different orbits, and an analysis of the spatiotemporal characteristic of ground movements. The focus of this paper is a detailed presentation of the workflow and an application-related interpretation of the results. The pool of methods used includes radar interferometry, but also spatiotemporal analysis and modeling. The overall objective of this comprehensive case study is to present the possibilities but also the limitations of the application of radar interferometry and to provide a perspective for future monitoring in post-mining areas.
\end{abstract}

Keywords: remote sensing; radar interferometry; ground movement; mining-related water management; mine water rise; coal mine; post-mining; Copernicus program; Sentinel-1

\section{Introduction}

Mining can affect its environment in a variety of ways. Impacts of extracting raw materials occur over a long period-the life cycle of the raw materials project, which consists of the exploration phase, the development and operational phase and finally the closure and after-care or post-mining phase. Typically, the largest impacts occur in the operational and the post-mining phase. Essential aspects are the intervention in the natural balance and its impact on biodiversity, the intervention in the water balance, the handling of mining waste, emissions of pollutants in water, soil and air and ground movements because of underground cavitation and water management activities. The characteristic and intensity of the impacts caused vary significantly depending on raw material-specific, technological, geological and ecological factors.

In German hard coal mining, similar to other European mining areas, the ground movements caused by underground cavitation and intervention in the natural water management are one of the major impacts that are the focus of numerous studies, e.g., [1-3]. In the operational phase of an underground mining project the mass removal from the Earth's interior results in a cavity, which, eventually, closes again under the pressure of the upper and lateral rock strata, unless it is immediately, and tightly backfilled after the mass removal. The closing of the cavities is done either by a gradual pressing in of the surrounding rock (converging), by bending of the upper rock strata or by breaking of the 
upper rock strata [4]. The depth and width of mining-related cavities, and the elastic and plastic properties of the overlying rock strata determine the type of surface deformation and thus the expected potential of hazards. In addition, the water management operated as part of the mining activity is another factor influencing ground movements that can occur in the mining lifecycle. Ground movements may still occur even after the mine has been closed, they are then resulting from a still continued closure of underground cavities or respectively due to changes in the water balance (e.g., by mine flooding processes). While the gradual closure of cavities in the underground is usually accompanied by subsidence of the Earth's surface, flooding processes in abandoned mines cause uplift processes on the Earth's surface. Regardless of the specific causes of ground movements, it is clear that a concept for long-term monitoring also in the post-operational phase is essential to manage related risks.

\subsection{Coal Mining Area Lugau/Oelsnitz}

The coalfield of Lugau/Oelsnitz (Figure 1) in the south of the federal state Saxony has an extent of about $6 \times 6 \mathrm{~km}^{2}$. It affects the places Lugau, Niederwuerschnitz, Neuwuerschnitz, Oelsnitz, Hohndorf, Roedlitz and Gersdorf. In addition to some forest, meadow and agricultural areas, the area is predominantly characterized or crossed by man-made structures, such as settlement areas, supply lines or roads. For better orientation and to get an idea of the spatial extent of the underground mine workings, the estimated $50 \mathrm{~cm}$ subsidence line from the active mining phase is shown on the overview map in Figure 1. The geological conditions can be described according to [5] as follows. In the Upper Carboniferous, a total of 14 coal seams were formed in the area. The coal seams alternate with shale, sandstone and iron ore layers and have a dip in the northwest from 10 to $15^{\circ}$. In the southern part of the basin the dip increases to values between $22^{\circ}$ and $27^{\circ}$. The thickness of the 14 mined coal seams varies between 0.5 and $5 \mathrm{~m}$. The mining conditions have been rather complicated, since the area is tectonically strongly influenced by graben structures. In addition to the major southwest oriented tectonic faults with displacement heights of $150 \mathrm{~m}$ (Pluto shaft fault) and $350 \mathrm{~m}$ (Roedlitzer fault), also smaller faults occur with displacement heights of 3-30 m. These have led to a strong tectonic division of the area with vertical offsets of the coal seams of up to $350 \mathrm{~m}$.

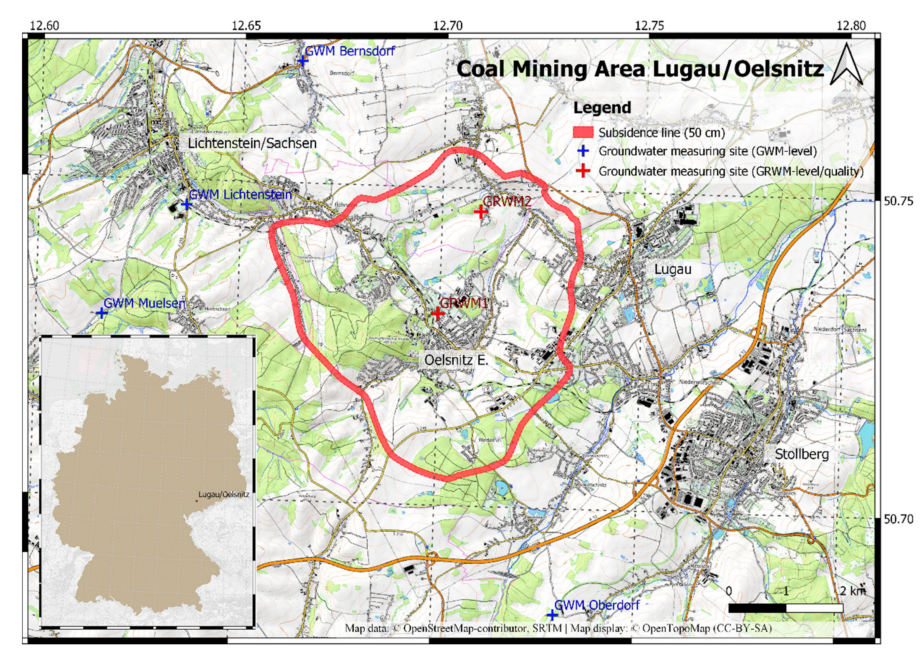

Figure 1. Location of the former coal mining area Lugau/Oelsnitz (Map data: ๑ OpenStreetMapcontributor. SRTM I Map display: () OpenTopoMap (CC-BY-SA)).

The active mining phase lasted from about 1848 to the year 1974. During this period, a total of approximately 140 million tons of coal have been extracted. Mine workings have been established corresponding to a volume of approximately 152 million $\mathrm{m}^{3}$. The deepest shafts or mine workings in the area are located at about $-700 \mathrm{~m} \mathrm{NN}$. With the surface being at approximately $300 \mathrm{~m} \mathrm{NN}$, this corresponds to a total depth of about $1000 \mathrm{~m}$. 
Dewatering has been carried out throughout the complete active mining phase. The water inflow has been low compared to other hard coal mining areas. The main impacts in the form of subsidence the surface is around the city Oelsnitz/E. and its southern periphery. A monitoring of related ground movements was already established during active mining. In the period from 1900 until 1974, leveling measurements have been performed in a two-year cycle of approximately 500 spatially uniformly distributed stations. Accordingly, ground subsidence of up to $17 \mathrm{~m}$ has been detected for this period [6]. Figure 2 shows the interpolated cumulative ground subsidence, which occurred in the time period from 1900 to 1970. Additionally, the location of the stations used for interpolation is shown. The interpolated map was created by combining the leveling data for each decade in the mentioned period and subsequent modeling of the accumulated subsidence per decade using the geostatistical Ordinary Kriging method with a spherical variogram model. All parts were then combined to a map of the total cumulative ground subsidence for 19001970 (Figure 2). A geostatistical approach was preferred to the application of simple non-statistical or geometric interpolation methods, since these simple methods determine the spatial relation independently of the real problem or relationship. In contrast, in geostatistics the spatial relation is quantified by fitting a spatial-dependence model to the available data during variography.

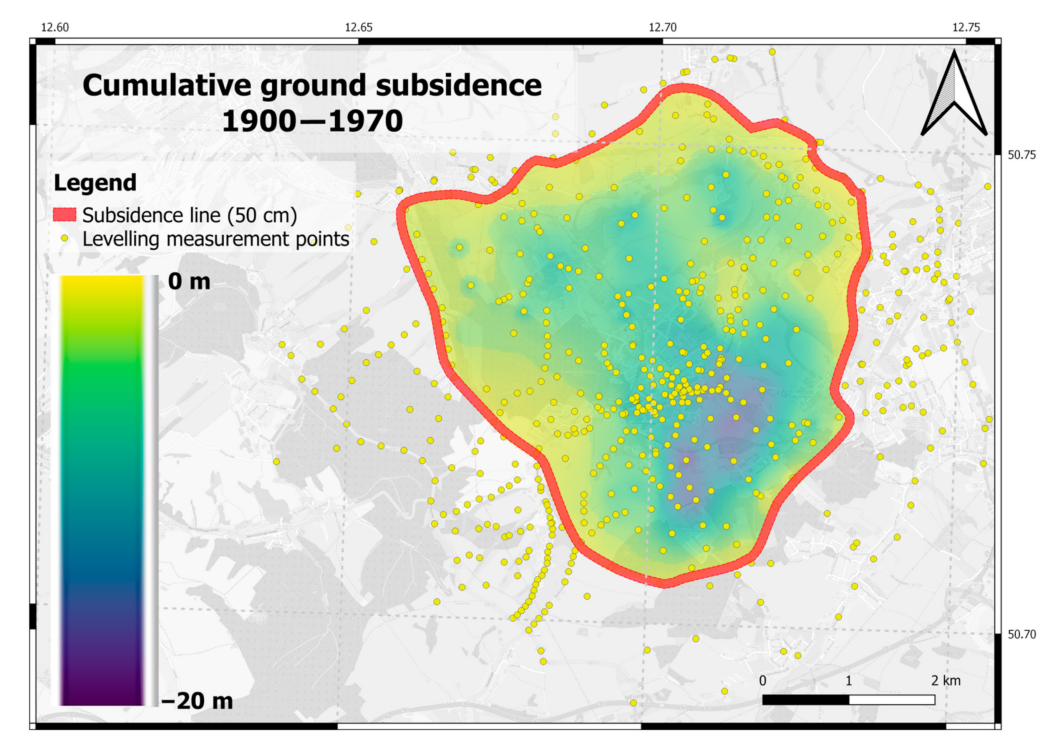

Figure 2. Ordinary Kriging interpolation of the cumulative subsidence based on leveling measurements during the active mining period from the year 1900 to 1970 (@ OpenStreetMap contributors).

\subsection{Monitoring Mine Water Rise and Associated Ground Movements}

At the end of the active mining phase in the beginning of the 1970s the water pumping stopped and the natural flooding of mine workings started. As part of the mine closure, all shafts, including those that were still in operation until the end, were kept safe by state-of-the-art backfilling techniques. Water gauges or alternative possibilities for the observation of the mine water rise have not been installed initially. Thus, the mine water rise has been unobserved for a long time and no information was available on the current flooding level. However, due to the low amount of inflowing water, the flooding process proceed has been very slow. The mine surveyor Curt Beyer already predicted a very long flooding period of more than 50 years in his "subsidence analysis" of 1974 [7]. Only in the years 2003/2004 a deep monitoring well (depth $634 \mathrm{~m}$ ) was installed in the area of city Oelsnitz and expanded to the first groundwater measuring site GRWM 1 (MKZ 52426003). From this point in time, a monitoring of mine water rise was possible [8]. This and all following mentioned water measuring sites are also shown in the overview map in Figure 1. In 2013/2014 a second ground water monitoring station GRWM 2 (MKZ 52420005) was established in the mining district in the area of commune Gersdorf. Both stations (GRWM 
1/GRWM 2) provide information on the water level but also on the water quality and on various water constituents. They are circa $2 \mathrm{~km}$ apart and have a hydraulic gradient of approximately $15 \mathrm{~m}$. The increase in mine water in the period studied (2006-2019) was approximately linear for both stations at a rate of approximately 10-12 m per year. However, hydrogeochemical studies have shown that the water of the two sites differs widely in its genesis and chemical composition $[9,10]$. There seems to be no or only very limited water exchange between the two monitored parts of the mining area [10]. In addition to the both measuring sites in the inner mining district, there are four more groundwater measuring sites around the area of interest, Muelsen (MKZ 52416007), Lichtenstein (MKZ 52410805) and Bernsdorf (MKZ 52411193) in the north-west and Oberdorf (MKZ 53420826) in the south-east. However, these measuring sites only provide water level information. In [11] it is already demonstrated that the three measuring sites in the north-west show a comparable behavior, and that the trend-adjusted fluctuations of these three levels correlate with the fluctuations of the measuring site GRWM2 with a time delay. According to this, fluctuations in the groundwater measuring sites in the north-west are correlated with the fluctuations in the mine water level (GRWM 2) $(\rho>0.75)$ with a time lag of approximately 2-3 months. For GRWM 1, no significant correlation could be determined.

As a result of the discontinuation of dewatering with associated rising mine water levels, there started a continuous lifting of the Earth's surface in the post-mining phase, which could be firstly proved by leveling measurements in the years 1996/1997, 2002, 2006 and 2014 [6]. Thereby approximately 100 selected stations of the former monitoring network are measured repeatedly on behalf of the responsible mining authority, the Saxon Mining Authority. A spatiotemporal modeling of the ground movements in the postmining phase showed that the uplift began in the north-west of the area of interest. In the time period from 1996/1997 to 2014 then a development of the uplift area from the north-west to the south-east could be determined [6]. The average movement rates that occurred were approximately $2-3 \mathrm{~mm}$ per year. Figure 3 shows the station locations of the very thinned out sparse measurement network for the leveling and the associated results of the modeling of the cumulative ground movements in the period 1997-2014 using again the Ordinary Kriging approach.

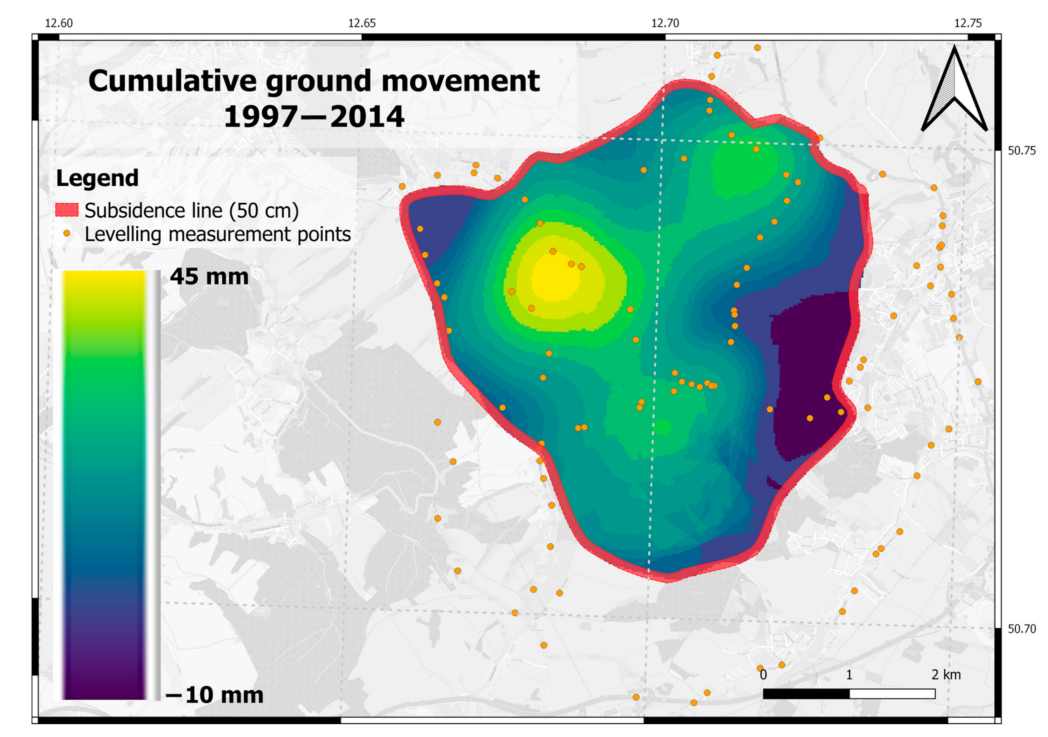

Figure 3. Ordinary Kriging interpolation of the cumulative ground movements based on the leveling measurements (1996/1997, 2002, 2006 and 2014) in the post-mining phase from the year 1997 to 2014 (C) OpenStreetMap contributors).

Disadvantages of monitoring in the post-mining phase based on only geometric leveling measurements are the large time intervals between the measuring campaigns, the unfavorable spatial distribution of the measuring stations (only in accessible areas) and the 
spatial point density and the high costs and timely effort of such a measuring campaign. Figure 3 clearly illustrates some of the weaknesses of monitoring ground movements on the basis of leveling measurements. Modeled ground movements are based on only a few data, especially in central areas, which in turn leads to substantial uncertainties in the spatial modeling.

An inexpensive option to extend the monitoring program is to use additional remote sensing data. With a supplementary monitoring based on the today widespread radar interferometry, a significantly improved monitoring of ground movements is possible. Radar interferometry is a remote sensing measurement method for determining large-scale ground movements by evaluating phase differences between radar recordings of different points in time. Usually, such radar images are taken from active synthetic aperture radar (SAR) systems $[12,13]$ and are evaluated with the radar interferometry approach, or more precisely with the differential interferometric synthetic aperture radar (DInSAR) [14]. One, of the main advantages of radar interferometry over classical leveling measurements is the significantly higher spatial and temporal data density, which can be achieved by a radar interferometric evaluation. In addition, with the free provision of data under the European Copernicus Program since 2014, a relatively cost-effective methodology for targeted supplementation of leveling measurements is available. Radar interferometry has become increasingly important over the past two decades. However, the term radar interferometry is only synonymous for very different methodological approaches for the interferometric evaluation of radar data. Depending on the application and the purpose of the evaluation, different methods are used. For the analysis of ground movements over longer periods of time, an evaluation using the persistent scatterer interferometry (PSI) $[15,16]$ is especially appropriate. The PSI method considers long time series of SAR scenes by considering the temporal change of the interferometric phase of stable point scatterers. Stable point scatterers are points that always backscatter in a similar way and dominate a resolution cell or pixel. These so-called persistent scatterers (PS) with stable backscatter properties can be, e.g., buildings, traffic routes, electricity pylons or similar objects. Therefore, PSI methods are particularly suitable for monitoring ground movements in mainly built-up areas.

\section{Study Area}

The project area was defined on a relatively large scale, considering the knowledge of the spatial extent of the subsidence phenomenon that occurred during the active mining phase. The area of interest (aoi) was defined by geographical coordinates (longitude/latitude) in the World Geodetic System 1984 (WGS84) as follows: longitude: $12.60-12.90^{\circ}$ /latitude: $50.60-12.90^{\circ}$. This area definition results in a region to be monitored of approximately $500 \mathrm{~km}^{2}$ with an east-west extension of approximately $25 \mathrm{~km}$ and north-south of approximately $20 \mathrm{~km}$. Whereby, the area of active ground movements in the Lugau/Oelsnitz mining district covers an area of approximately $36 \mathrm{~km}^{2}$ with around $6 \mathrm{~km}$ extension in east-west and north-south direction. The project area is predominantly characterized or crossed by man-made structures, such as settlement areas, supply lines or roads but also contains some forest, meadow and agricultural areas.

\section{Data and Methods}

In this section the data and methods for the monitoring and analysis of ground movements are briefly introduced.

\subsection{Python Data Analysis}

Data analysis with the Python programming language is always a good choice for practitioners in data science and data analytics. Python is a complete programming language on which many different data science applications can be developed. It is easy to learn with a steady learning curve. So, the low learning curve and flexibility of Python are some of the reasons, why Python is today one of the fastest growing languages in 
both academic and business environments. In addition to an extensive standard library, Python offers a variety of extension packages for different applications. In the context of spatiotemporal data analysis, the packages NumPy, Pandas, GeoPandas and Statsmodels have emerged to be essential libraries. NumPy stands for "Numerical Python" and is an open source module of Python, which provides fast mathematical computation on arrays and matrices. Pandas is a further open-source Python library built on top of NumPy providing high-performance, easy-to-use data structures and data analysis tools. It allows an efficient organization of observation data and a fast, statistical data analysis and data preparation and cleaning. Pandas is suitable for organizing and processing a wide variety of different kinds of data, but it shows particular strengths in the processing of time series data. GeoPandas is a project to add support for geographic data to Pandas objects with the objective to make working with geospatial data in Python easy to use. Additionally, Statsmodels is a Python module that provides classes and functions for the estimation of many different statistical models, and for conducting statistical tests, and statistical data exploration. Additionally, also Matplotlib [17] should be mentioned, a plotting library to produce high quality figures.

\subsection{Long-Term Ground Movement Monitoring Using Radar Interferometry}

Radar interferometry is a remote sensing measurement method for determining largescale ground movements, such as those caused by mining activities. For this purpose, radar images of different times but covering the same area are evaluated. Usually, such radar images are taken from active SAR systems. An introduction to the basics of these systems is given, e.g., by M. Skolnik [12,13] and a comprehensive introduction to the theoretical foundations of radar interferometric evaluation is given, e.g., by R. Hanssen [14] and can be briefly summarized as follows. An active radar sensor mounted on a satellite sends out a radar signal to the Earth's surface and measures than the amplitude and the phase of the reflected signal. The amplitude describes the strength of the signal that is recorded and the phase, or more precisely the phase difference between the transmitted and the received signal, is an ambiguous measure $(-\pi$ to $\pi)$ of the distance between sensor and Earth surface. The phase information is crucial for the determination of deformations, because a difference in phase between two sequential measurements indicates that the travel path of the signal has changed. Additionally, since the wavelength of the radar signal is known very precisely, the corresponding relative deformations can be determined with millimeter precision from phase differences. The observed phase difference between two points in time is also called the interferometric phase.

However, the interferometric phase $\Phi_{\text {InSAR }}$ is influenced by several factors, it is dependent on the recording geometry $\Phi_{\mathrm{Geom}}$, the topography $\Phi_{\mathrm{Topo}}$, the atmospheric conditions $\Phi_{\text {Atmo }}$ and of course by the deformation to be recorded $\Phi_{\text {Defo }}$. In addition, a certain amount of interference/noise $\Phi$ noise is also present in every interferometric phase. This results in the following composition of the interferometric phase [18]:

$$
\Phi_{\text {InSAR }}=\Phi_{\text {Geom }}+\Phi_{\text {Topo }}+\Phi_{\text {Atmo }}+\Phi_{\text {Defo }}+\Phi_{\text {noise }}
$$

The phase differences can be visualized in a phase difference image, which is also referred to as an interferogram. The challenge of an interferometric evaluation is now to determine the individual components in the best possible way in order to ultimately be able to extract the information about the deformation as precisely as possible. The interference component or the noise is based on signal decorrelations, which are caused by various sources of error. The noise component $\Phi_{\text {noise }}$ can be partially reduced with the help of phase filters. The geometry-related phase component $\Phi_{\mathrm{Geom}}$ is also called the "flat-earth" influence and results from the recording geometry. It leads to a continuous change of the phase in the range direction and is determined using a reference surface. For this purpose, information about the exact orbits in the form of satellite ephemeris or position vectors at discrete points in time are required. These can usually be obtained from the data provider during the evaluation. The topography-related phase component 
$\Phi_{\text {Topo }}$ results from the height differences of the terrain surface and can be determined with the help of a known digital elevation model (DEM). Additionally, last but not least the atmospheric phase component $\Phi_{\mathrm{Atmo}}$, which is caused by different atmospheric conditions or disturbances during the acquisition of the SAR images at different points in time. These lead to signal delays and correspondingly to path differences due to refractions in the ionosphere and troposphere [18]. To determine the atmospheric phase component, e.g., atmospheric models or simple filter methods, are used. For example, it is possible to take advantage of the fact that the influence of the atmosphere is not correlated with time, in contrast to the deformation. A detailed analysis of the determination of the individual phase components including a consideration of the corresponding error influences can be found in [14] or [18]. In general, the quality of the interferometric phase can be described with the help of coherence, which is a measure of the similarity of multiple SAR images. It describes the change in the amplitude and phase information of each pixel. The range of values for the coherence is between zero and one, where $c o h=0$ means complete decorrelation, while coh $=1$ means complete coherence of the recordings.

The radar interferometry has become increasingly important in the last two decades, also due to the high availability of suitable imaging radar systems with various L-band, C-band and X-band sensors. As mentioned already in the introduction, the term radar interferometry is only a synonym for a whole series of methodical approaches for the interferometric evaluation of radar data. Different methods are used depending on the application and the purpose of the evaluation. For the analysis of ground movements over longer periods of time, an evaluation with a so-called "Persistent Scatterer Interferometry" (PSI) approach $[15,16]$ has proven itself in various studies and can be recommended. The PSI method evaluates long time series of SAR scenes by observing the temporal change in the phase of stable point scatterers. Stable point scatterers are points that always backscatter in a similar manner and that dominate a resolution cell or pixel. These persistent scatterers (PS) with stable backscatter properties can be, e.g., buildings, traffic routes, electricity pylons or similar objects. Therefore, PSI methods are particularly suitable for monitoring ground movements in urban areas. A large number of different variations of the PSI approach are described in the literature. A well-made overview of various developments is provided by Crosetto et al. [19].

For the evaluation in the study area the approach of Hooper et al. [20] was used. This approach exploits a method of selecting the PS points using phase properties, which is suitable for finding natural, low amplitude targets with phase stability that cannot be identified by other amplitude-based algorithms [19]. A further practical reason for the choice was that this approach forms the basis of the freely available PSI software package StaMPS [21,22]. Note, the software is based on Matlab ${ }^{\circledR}$, therefore a licensed version of the commercial Matlab ${ }^{\circledR}$ software (https: / / www.mathworks.com accessed on 1 February 2021) is required.

\subsubsection{Consideration of the 3D Nature of Deformations}

Mining-related ground movements are three-dimensional deformations of the Earth's surface that vary over time. With radar interferometry, however, initially only movements in the direction of line of sight (LOS) can be determined. In order to be able to fully describe such three-dimensional ground movements, three radar data sets would have to be available, which were recorded in different directions and which overlap in space and time [14]. However, since all available radar sensors only have approximately a northsouth (ascending) or south-north (descending) flight direction, the viewing directions (looking to the right at approximately $90^{\circ}$ to the flight direction) are either from west to east (ascending) or from east to west (descending). As a result, the currently available radar data can only be used to derive changes in altitude (vertical component) and in the east-west direction (horizontal component). However, this configuration is not sensitive for the determination of horizontal movements in the north-south direction. In the past, methods such as pixel offset tracking [23] or multiple aperture interferometry (MAI) [24] 
approaches were used to resolve this problem. Although these approaches allow the monitoring of the temporal development of ground movements in 3D when deformations of great magnitude occur, e.g., in the case of seismic events, they are currently not able to determine displacements in the north-south direction with the accuracy required for mining applications. A well-made overview of the past and current developments in this field is provided in [25].

Changes in altitude can be derived solely from the change in line of sight $\left(\Delta \mathrm{d}_{\mathrm{LOS}}\right)$ of one orbit (Equation (1)), but only under the assumption that no horizontal shifts have occurred. Whereby $\theta_{\mathrm{i}}$ denotes the angle of view or incidence angle.

$$
\Delta \mathrm{d}_{\mathrm{Z}}=\frac{\Delta \mathrm{d}_{\mathrm{LOS}}}{\cos \left(\theta_{\mathrm{i}}\right)}
$$

However, evaluating only one orbit can lead to misinterpretations of the changes in altitude in areas with actually occurring horizontal movements, i.e., depending on the angle of incidence, this can lead to a significant overestimation or underestimation of the vertical movement component [18]. Therefore, the joint evaluation of an ascending and descending orbit is generally to be favored. Additionally, because this is the only way to additionally determine the horizontal east-west component.

For a joint evaluation of two orbits in different directions, the shifts in the viewing direction (LOS) are first determined for both orbits independently of one another. However, when selecting the orbits, care should be taken to guarantee that the mean incidence angles of the radar radiation are as similar as possible, in order to ensure that both orbits have a comparable sensitivity with regard to the movement components in the vertical and horizontal direction. To determine the vertical and horizontal (east-west) movement from two independently evaluated orbits, the LOS movement of both orbits is necessary for each point under consideration. However, the position of the resulting PS points differs when evaluating different orbits due to the varying viewing angles and directions and occurring positional inaccuracies. The positional accuracy of PSI point clouds is affected by various factors in the geocoding process, whereby atmospheric influences, earth tides, tectonics and timing errors (azimuth shift) being the dominant factors [26]. The magnitude of these errors is in the range from centimeters to meters. In Schubert et al. [27], the absolute position accuracy was determined from images of Sentinel-1 in azimuth and range direction, in the best case in the order of several decimeters. Basically, two different approaches are possible to overcome the shortcoming when two independently evaluated orbits are combined. The first option is to interpolate the LOS values of one PSI point cloud to the position of the second PSI point cloud from the other orbit. Additionally, the second option is to overlay both PSI point clouds by a regular grid and to interpolate the LOS values of both orbits on this new regular grid. Regardless of the method chosen, the calculation of the vertical $\left(d_{Z}\right)$ and horizontal $\left(d_{E-W}\right)$ component can be done by solving the following system of equation (Equation (3)):

$$
\left[\begin{array}{l}
d_{\text {asc }}^{\operatorname{LOS}} \\
d_{\text {desc }}^{L O S}
\end{array}\right]=\left[\begin{array}{cc}
\cos \left(\theta_{\text {asc }}\right) & \frac{\sin \left(\theta_{\text {asc }}\right)}{\cos (\Delta \alpha)} \\
\cos \left(\theta_{\text {desc }}\right) & \sin \left(\theta_{\text {desc }}\right)
\end{array}\right] \cdot\left[\begin{array}{c}
d_{Z} \\
d_{E-W}
\end{array}\right]
$$

where $\theta_{\text {asc }}$ and $\theta_{\text {desc }}$ denote the corresponding incidence angles of the two orbits and $\Delta \alpha$ denotes the difference between the two course angles $\alpha_{\text {asc }}^{h}$ and $\alpha_{\text {desc }}^{h}$ (heading angles).

\subsubsection{Derivation of Ground Movement Rates}

The resulting PSI time series of the relative ground movements from the interferometric evaluation consist of a trend component and stochastic fluctuations. The latter result from signal fluctuations with unknown cause, systematic and gross measurement errors (e.g., due to atmospheric disturbances or phase unwrapping errors) and noise [28] and cannot be completely avoided. In the course of an interferometric evaluation with the PSI approach the trend component is usually what we are interested in. The trend is usually only determined by linear regression over the entire analysis period and an 
average movement rate per year $(\mathrm{mm} / \mathrm{y})$ is derived from this trend. This means that radar interferometry is actually not a pure measurement method, but rather it already includes further processing of the measured variable, e.g., to parameters of the ground movement to be determined [29]. Apart from this fact, the basic assumption of a linear movement trend is not always suitable. For some areas but also especially in principle with an increasing observation period, the choice of a linear trend model must be considered critically. If there are signs of non-linear behavior of the PSI time series in certain areas, it is better to use higher-order deterministic trend models or statistical moving window approaches to derive an appropriate movement trend.

\subsubsection{Software Solutions}

The radar interferometric evaluation is based on a number of software tools, which are briefly presented below. The preprocessing of the radar data up to the calculation of the interferograms between the master scene and all slave scenes was carried out with the help of the freely available Sentinel Application Platform (SNAP) of the European Space Agency (ESA) and the Snap2stamps [30] script collection. The StaMPS software is used for the actual evaluation with the persistent scatterer interferometry (PSI) method. In addition, the Python programming language and geographic information systems (such as QGIS) were used in post-processing for the evaluation of the results and for the analysis and derivation of movement trends or spatial-temporal modeling.

\section{Sentinel Application Platform (SNAP)}

The Sentinel Application Platform (SNAP) is a software solution developed on behalf of the European Space Agency (ESA) as a common architecture for the Sentinel Toolboxes developed by ESA. It is provided for free on the Scientific Toolbox Exploration Platform (STEP) website (http:/ / step.esa.int/main/toolboxes/snap/ accessed on 1 February 2021). The different Sentinel toolboxes contain various tools that are helpful when processing the data from the Sentinel satellites. The Sentinel-1 Toolbox (S1TBX) is required for processing Sentinel-1 radar data. The functions of the toolboxes can be called up via the graphical user interface (GUI) or also via scripts or command line calls. In addition, SNAP offers a so-called graph processing framework (GPF) to create and execute recurring workflows in xml-format.

\section{Snap2Stamps}

Snap2stamps [30] is a collection of Python scripts, workflow descriptions in xmlformat, as input for the SNAP GPF, and an additional configuration file. The package allows to automate the preprocessing of the radar scenes with SNAP for a subsequent PSI evaluation with the StaMPS software. The script collection was designed for processing with the software SNAP (version 6.0) and Python 2.7. For use with other program or Python versions, adjustments may be necessary. The package is available at: https:// zenodo.org/record/1322353\#.XKxdOKRCTmE accessed on 1 February 2021.

\section{Stanford Method for Persistent Scatterers (StaMPS)}

Stanford method for persistent scatterers (StaMPS) is a software package for interferometric evaluation using the persistent scatterer interferometry (PSI) approach [21,22]. The software is based on Matlab ${ }^{\circledR}$ and C ++ . A licensed version of the commercial Matlab ${ }^{\circledR}$ software (https: / / www.mathworks.com accessed on 1 February 2021) is therefore required. StaMPS was originally developed at Stanford University and later developed further at the University of Iceland, Delft University of Technology and University of Leeds. The current version by Andy Hooper (version 4.1b1) has been available for free on GitHub (https://github.com/dbekaert/StaMPS/releases/tag/v4.1-beta accessed on 1 February 2021) since August 2018. 


\subsection{SAR Data}

The radar data used in this study comes from the Sentinel-1 satellites (Sentinel-1 A/Sentinel-1 B), which belong to the family of sentinel satellites and are part of the Copernicus program. The Copernicus program, formerly known as the Global Monitoring for Environment and Security (GMES) is the European earth observation program. The Copernicus Program is coordinated and managed by the European Commission and it is implemented in partnership with the Member States, the European Space Agency (ESA), the European Organization for the Use of Meteorological Satellites (EUMETSAT), the European Center for Medium-Range Weather Forecasts (ECMWF), the EU agencies and Mercator Océan. The program can be divided in a space component with the Sentinel satellites, which is the heart of the program, and some information services, which use data from the space component and additional Earth observation data from in-situ measurements or from commercial contributing satellite missions. The space component is managed by ESA and provides users with satellite data from the Sentinel satellites without costs.

The Sentinel-1 satellites are equipped with C-band radar sensors, which are working with a wavelength of $\lambda=0.055466 \mathrm{~m}$ and allow recording in single polarization ( $\mathrm{HH}$ or $\mathrm{VV}$ ) and dual polarization $(\mathrm{HH}+\mathrm{HV}$ or $\mathrm{VV}+\mathrm{VH})$. The satellites have a right-looking recording setting, where the angle of view or incidence angle varies between 20 and $45^{\circ}$. In principle, the instruments enable different recording modes, which differ in the width of the recording strips and in the spatial resolution. The interferometric wide swath (IW) mode is the operational standard mode of the Sentinel-1 satellites and hence also used for the radar interferometric evaluation in the study area. It acquires data with a $250 \mathrm{~km}$ swath and with a spatial resolution of $5 \mathrm{~m} \times 20 \mathrm{~m}$ (range direction $\times$ azimuth direction). In general, and independently of the acquisition mode different data products are available: SAR Level-0, Level-1 Single Look Complex (SLC), Level-1 Ground Range Detected (GRD) and Level-2 Ocean (OCN). The use of Level-1 SLC data is necessary for the radar interferometric evaluation, since the phase information was also retained in these in addition to the amplitudes. For more information about the acquisition modes, data products and additional technical information please refer to the official user guide provided by the ESA (https:/ / sentinel.esa.int/web/sentinel/user-guides/sentinel-1-sar accessed on 1 February 2021).

Each IW-SLC product consists of three substrips, the subswaths (IW1, IW2 and IW3), which in turn are made up of usually nine so-called bursts. In order to guarantee spatial coverage, the individual bursts and subswaths each slightly overlap. Figure 4 shows the structure of a Sentinel-1 scene (IW mode) from a descending orbit. When recording a descending orbit, the subswaths are numbered from right to left and the bursts from top to bottom. When recording an ascending orbit, the numbering is exactly the opposite, i.e., always in the viewing direction (subswaths) or flight direction (bursts).

The Lugau/Oelsnitz mining district is basically covered by four Sentinel-1 orbits (Table 1), whereby the area of interest (aoi) is located in different subswaths depending on the orbit. In order to prevent distortions in a combined evaluation of ascending and descending orbits, care should be taken when selecting the orbits that the investigation area (aoi) lies in the same subswath if possible. This results in comparable incidence angles for both orbits and ensures that both orbits have a comparable sensitivity with regard to the movement components in the vertical and east-west direction. For this reason, the relative orbit 146 (asc) and 168 (desc) was selected and the investigation period was defined, based on the availability of Sentinel-1 data, from October 2014 to December 2019. The mean incidence angles for the study area were as follows: $\theta_{\text {asc }}=32.9795^{\circ}$ and $\theta_{\text {desc }}=35.2656^{\circ}$ and the difference of the two course angles was $\Delta \alpha=159.4202^{\circ}$. 


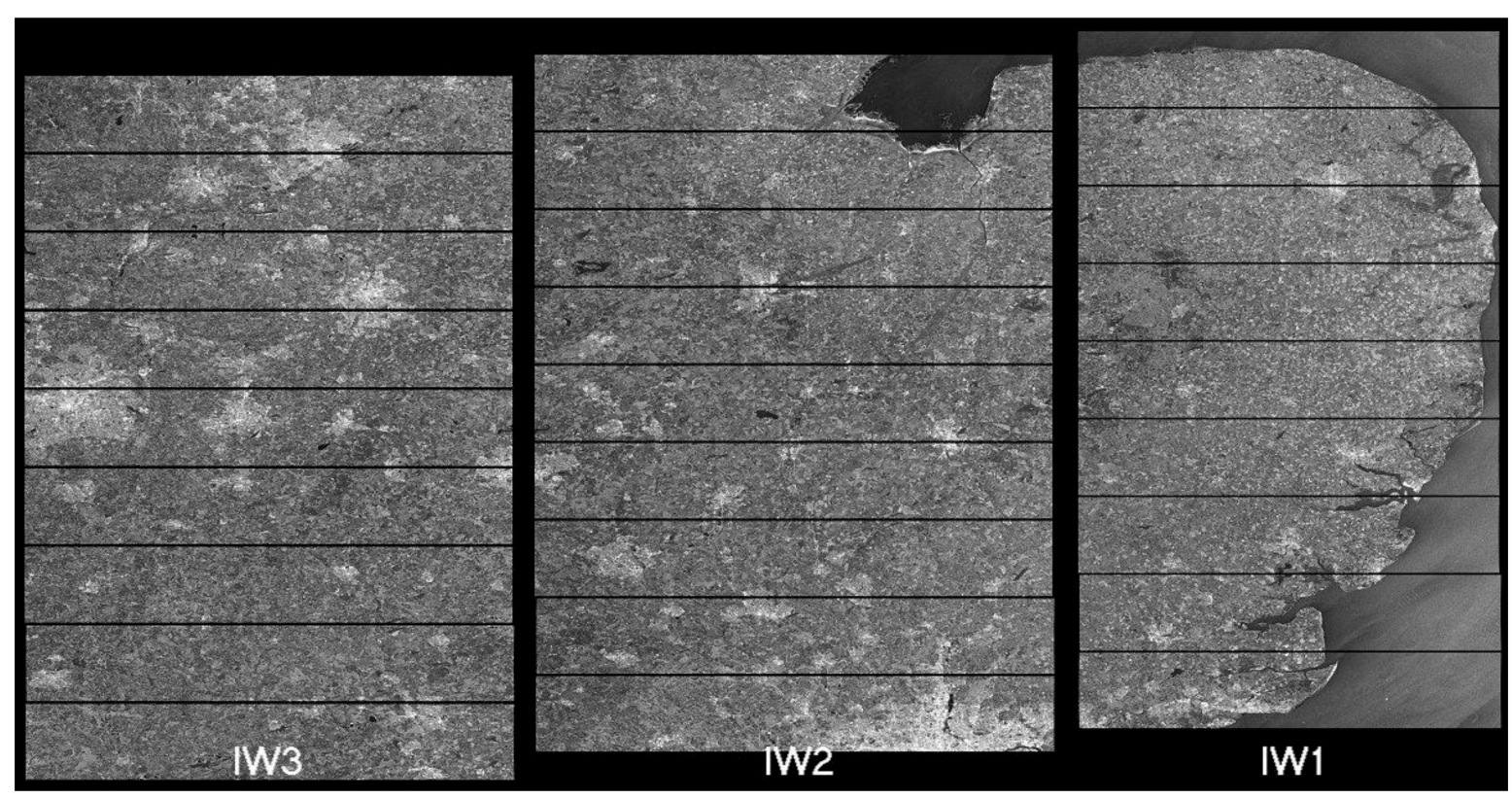

Figure 4. Structure of a Sentinel-1 image (IW mode) with subswaths and bursts (source: ESA website).

Table 1. Overview about available Sentinel-1 orbits for the study area.

\begin{tabular}{ccc}
\hline Relative Orbit No. & Orbit Direction & Sub-Swath Contains Aoi \\
\hline 95 & descending & IW3 \\
\hline 168 & descending & IW1 \\
\hline 146 & ascending & IW1 \\
\hline 44 & ascending & IW2 \\
\hline
\end{tabular}

Table 2 shows an overview of the number of available Sentinel-1 images for both selected orbits. For the period October 2014 to September 2016 there was usually a recording every 12 days available and for the remaining period from September 2016 to December 2019, the time interval between two recordings was usually 6 days. This higher data density since September 2016was related to the start of the second Sentinel-1 radar satellite (1B) in 2016. Exceptions regarding the temporal resolution for the available data were caused by some faulty and therefore unsuitable images.

Table 2. Overview of the available Sentinel-1 scenes (Lugau/Oelsnitz) in the period 2014-2019.

\begin{tabular}{cccccccc}
\hline rel. Orbit & $\mathbf{2 0 1 4}$ & $\mathbf{2 0 1 5}$ & $\mathbf{2 0 1 6}$ & $\mathbf{2 0 1 7}$ & $\mathbf{2 0 1 8}$ & $\mathbf{2 0 1 9}$ & Total \\
\hline 168 (desc) & 7 & 23 & 32 & 55 & 57 & 59 & 233 \\
\hline $146(\mathrm{asc})$ & 8 & 26 & 38 & 60 & 61 & 59 & 252 \\
\hline
\end{tabular}

The first radar scene from October 2014 represents the time reference for each orbit, i.e., these recordings define the time $t=0$, where the displacement on all PSI points is zero. The spatial reference is defined by an area in the north-west of the study area near Lichtenstein/Saxony in which no significant ground movements are to be expected. The spatial reference area was defined by specifying a coordinate pair (Lon: $12.625^{\circ} /$ Lat: $\left.50.760^{\circ}\right)$ and a radius $(125 \mathrm{~m})$. The scene from 24 November 2017 was identified and selected as the optimal master scene for the descending orbit (168) and the scene from 22 November 2017 for the ascending orbit (146). The selection of the optimal master image was based on an estimate of the expected coherence for the stack of SAR images. It is 
chosen to maximize the expected coherence of the stack and can be carried out with the SNAP Tool "Optimal InSAR Master Selection". For the final combination of both orbits, a resampling of the resulting time series was first carried out for a uniform starting time $\left(\mathrm{t}_{0}=\right.$ 5 October 2014) and a uniform time interval of 6 days. The values were then transferred from one point cloud to another. Therefor we iterated over the points of the point cloud of the descending orbit and for each point it was checked whether a corresponding near-by point exists in the other point cloud, provided that a maximum distance of $25 \mathrm{~m}$ was not exceeded.

\section{Results and Discussion}

In this section the current results and the associated discussion is presented.

\subsection{PSI Evaluation Results}

Table 3 shows an overview of the standard deviation of the estimated LOS velocity, where the DEM and orbit errors were subtracted. Only small standard deviations are shown for the study area and there were no spatial areas with significantly larger standard deviations that indicate atmospheric anomalies or unwrapping errors. Table 4 then gave an overview (quantity and quality) of the two independent evaluations for the ascending and descending orbit and their combination. Figures 5 and 6 show the average rate of movement in the viewing direction (LOS) for the PSI point clouds of the descending and ascending orbit.

Figure 7 then shows the resulting point cloud from the combination of the ascending and descending orbit for the core area of the Lugau/Oelsnitz mining area. For better orientation, a topographic map and the $50 \mathrm{~cm}$ subsidence line from the active mining phase were shown. The PS points are shown in color according to their values for the mean vertical ground movement rate, determined by linear regression over the entire analysis period from $10 / 2014$ to $12 / 2019$.

Table 3. Overview of the independent persistent scatterer interferometry (PSI) analysis (asc/desc) for time period October 2014 to December 2019.

\begin{tabular}{ccccccc}
\hline \multirow{2}{*}{ Orbit } & \multirow{2}{*}{$\begin{array}{c}\text { No. of PSI } \\
\text { Points }\end{array}$} & \multicolumn{5}{c}{$\begin{array}{c}\text { Std. Dev of LOS Velocity } \\
(\mathbf{m m})\end{array}$} \\
\cline { 3 - 7 } & & Min & Q25 & Mean & Q75 & Max \\
\hline Descending (168) & 21203 & 0.07 & 0.14 & 0.16 & 0.17 & 0.37 \\
\hline Ascending (146) & 28040 & 0.07 & 0.16 & 0.18 & 0.19 & 0.37 \\
\hline
\end{tabular}

Table 4. Overview PSI point cloud quality of single orbit and combined datasets.

\begin{tabular}{cccccccc}
\hline \multirow{2}{*}{ Orbit } & \multirow{2}{*}{$\begin{array}{c}\text { No. of PSI } \\
\text { Points }\end{array}$} & Min & Mean & Max & Q25 & Q50 & Q75 \\
\cline { 3 - 8 } & 21203 & 0.31 & 0.89 & 0.99 & 0.85 & 0.91 & 0.96 \\
\hline Descending (168) & 28040 & 0.30 & 0.89 & 0.99 & 0.85 & 0.91 & 0.96 \\
\hline Ascending (146) & 17073 & 0.38 & 0.90 & 0.99 & 0.87 & 0.91 & 0.95 \\
\hline Combined (asc/desc) & & & & & &
\end{tabular}




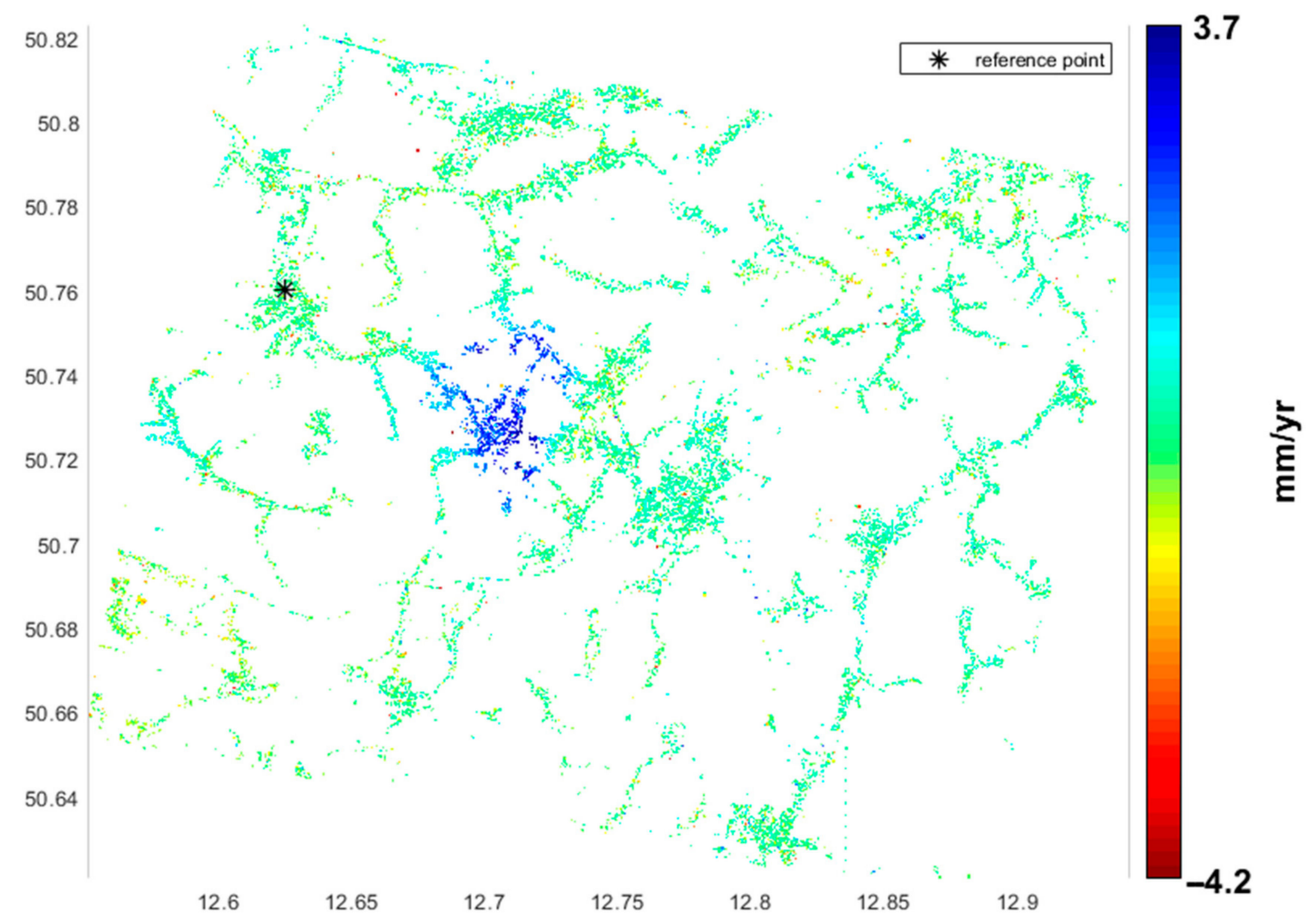

Figure 5. PSI point cloud (descending orbit 168)—-mean ground movement rate in line of sight (LOS).

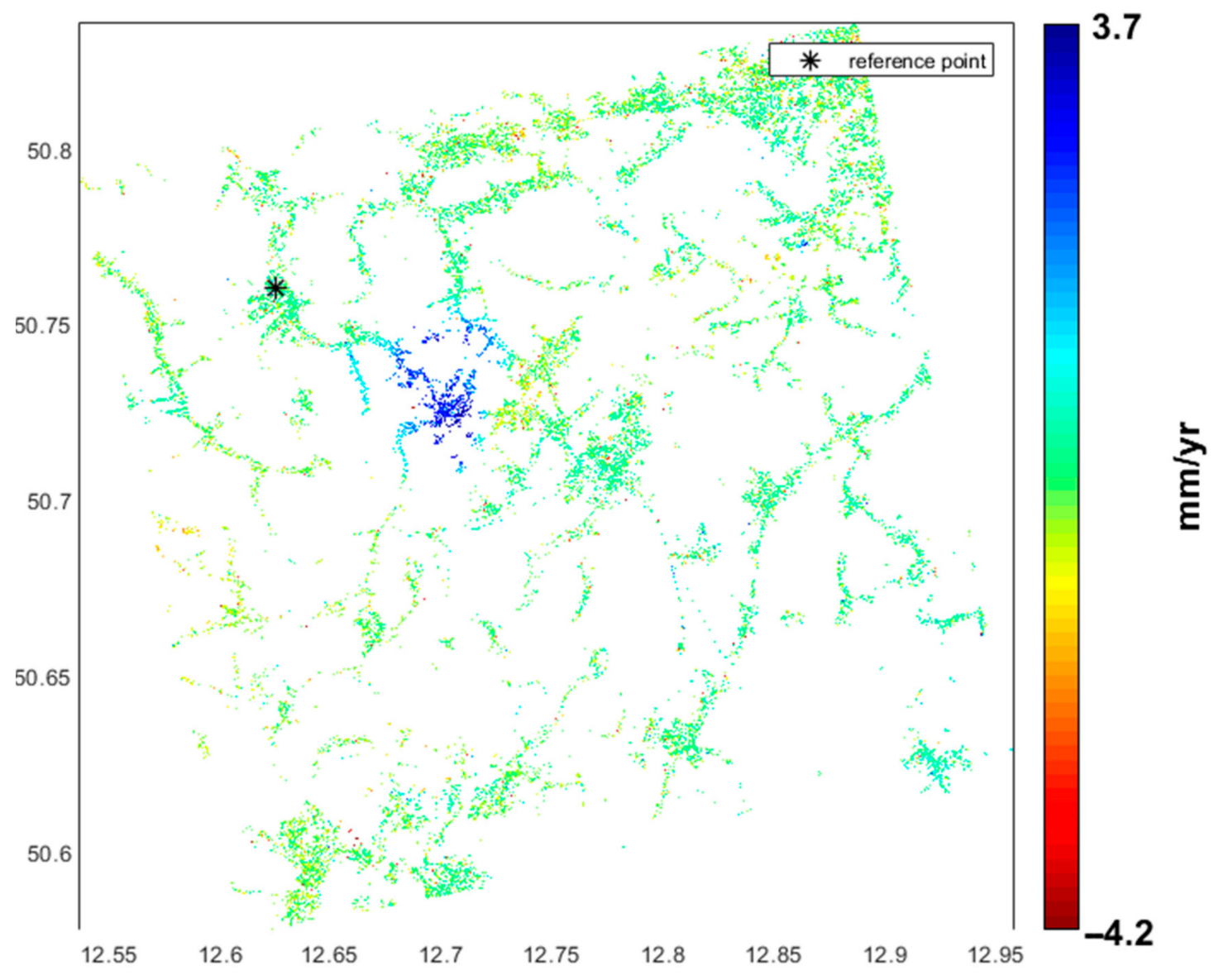

Figure 6. PSI point cloud (ascending orbit 146)—-mean ground movement rate in line of sight (LOS). 


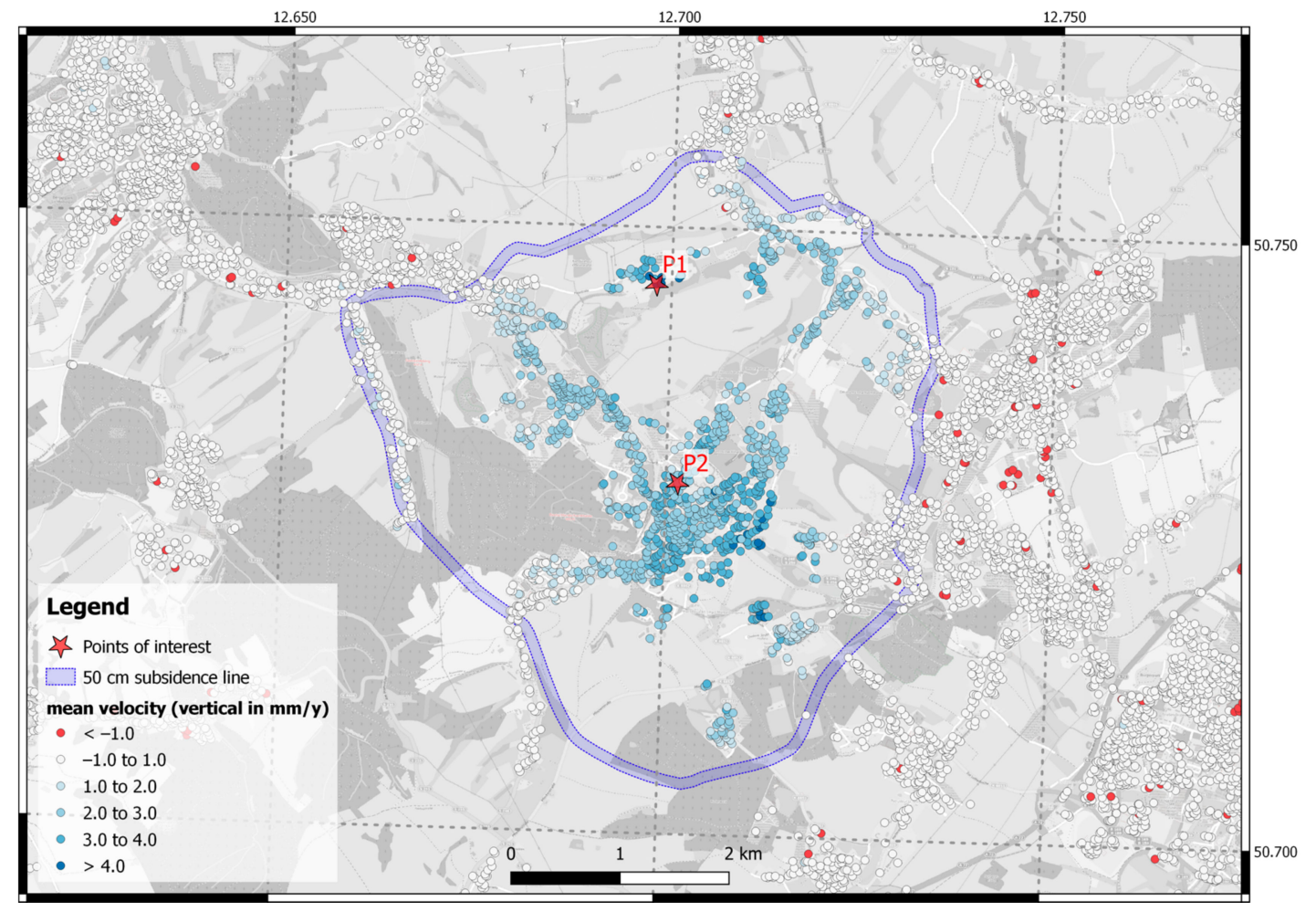

Figure 7. PSI point cloud from the combined evaluation of ascending and descending orbit—mean vertical ground movement rate for the investigation period 10/2014-12/2019 (Basemap: (C) OpenStreetMap contributors).

The results of the radar interferometry show a very good delimitation of the moving areas, due to the mine water rise, from stable areas. For the visualization of combined PSI results classes of observations with $1 \mathrm{~mm}$ wide were formed. Declared ground movements with an amount less than $1 \mathrm{~mm}$ were treated as neutral, since from a practical point of view no reliable statements were possible below this limit due to the various error influences of radar interferometry. Figure 7 also shows some PS points that indicate subsidence in areas of the study area that are actually motionless. An analysis of these points show that these PS points had a clearly lower coherence value compared to neighboring points and were therefore not representative of the large-scale movement behavior in the area. These points should therefore be filtered out for a subsequent spatial modeling of the movements. Figure 8 shows the determined mean horizontal ground movement rate (east-west direction) from the combination of the ascending and descending orbit. As before, only the core area of the Lugau/Oelsnitz mining area was shown. It can be seen that the horizontal (east-west) ground movements occurred mainly on the eastern or western flank of the current uplift area. However, the amounts of these movements of 1-2 mm per year for the period 2014-2019 were very low.

The great advantage of radar interferometry compared to the conventional terrestrial measurement methods (leveling) used so far was the significantly greater spatial and temporal information density that this method could provide. The only exceptions were predominantly rural areas with a high proportion of vegetation (forests, meadows, etc.), here the distribution of permanent backscatter (PS points) was much less or even nonexistent. In these areas, however, by setting up artificial radar targets, so-called corner reflectors, additional coherent point targets could be created in order to increase the point density. A corner reflector is a retroreflector that consists of three mutually perpendicular, intersecting flat surfaces through which the incoming radar radiation is reflected back directly to the source. Corner reflectors are usually characterized by a significantly higher 
reflectivity compared to the surrounding objects (backscatters), so that these dominate the echo of the resolution cell or pixel [31]. This means that they behave like point targets and show a particularly strong backscatter (intensity) in the SAR images. In addition, corner reflectors are the only way to validate the results of a PSI analysis using other measuring methods, since the geometry of the corner reflectors defines a known scattering center, which can be measured by a terrestrial leveling or by means of a GNSS monitoring station and thus allows a validation or connection to known position and altitude measuring networks. For a combined evaluation strategy as it is carried out in the investigation area, it is important to ensure, that the locations of such corner reflectors must be occupied twice, i.e., each location consists of two corner reflectors for recording the ascending and descending orbit. The individual corner reflectors are aligned so that the azimuth and the height of the central axis vector are aligned with the SAR satellites, i.e., coincide with the line of sight (LOS). It should be noted that the required size of the corner reflectors depends on the requirements for accuracy and the radar satellites used, i.e., with the same accuracy requirements, the necessary size of a reflector, e.g., for TerraSAR X, is smaller than reflectors that are planned and used with Sentinel-1 data. In [32] theoretically necessary sizes of corner reflectors were determined for various SAR systems in order to achieve a defined level of accuracy. Accordingly, corner reflectors with an edge length of $1.5 \mathrm{~m}$ are necessary for C-band data such as those from the Sentinel-1 sensors in order to achieve an error of less than $1 \mathrm{~mm}$.

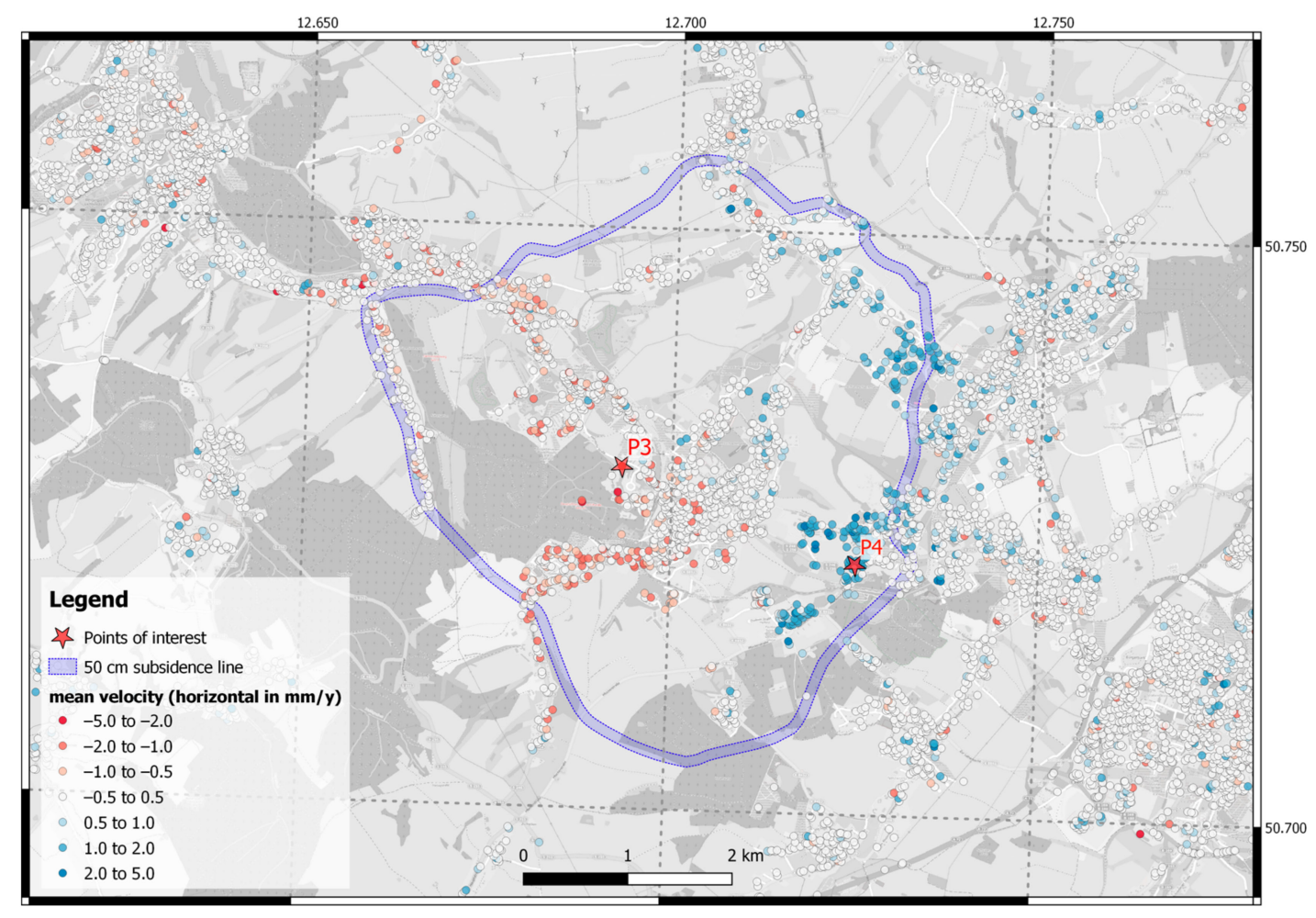

Figure 8. PSI point cloud from the combined evaluation of ascending and descending orbit-mean horizontal (east-west) ground movement rate for the investigation period 10/2014-12/2019 (Basemap: (C) OpenStreetMap contributors).

\subsection{Analysis of the Ground Movement Behavior and Derivation of Movement Rates}

Before a detailed analysis of the movement behavior, obvious outliers in the time series data were eliminated, for this the sliding or rolling standard deviation with a time window of one year was determined and it was checked whether the points of a time series were in the range of $\pm 2 \sigma$. If this is not the case, these points were removed from the time series. 
As already explained in Section 3 (Data and Methods), the assumption of a linear movement behavior in the study area was not always suitable. Figures 9 and 10 illustrate this using the selected PS points P1 and P2 from the study area. The location of these points is shown in Figure 7. The time series of the vertical ground movement is shown, as well as a comparison of various derived movement trends. The curve "All Years" shows the result of a linear regression over the entire observation period and the mean movement rate derived from it, as provided as standard output by the StaMPS software. The curve "MovAv_Trend" shows the moving average of the time series for a window size of 12 months and thus provides a good indication of changes in the movement behavior of the recorded backscatter (PS points). The trend curve "MovAv_Trend" was than approximated by piecewise linear functions in order to consider such changes in the movement behavior over time in the modeling process, but at the same time to keep the effort involved within practical limits. Therefore, a total of three movement rates (2014/2015, 2016/2017 and 2018/2019) for different time intervals were derived in the investigation period. Figures 9 and 10 show very well that these partially valid movement rates depict the dynamics of the ground movements sufficiently well. In the case of Figure 9, it is the PS point P1 north of the city of Oelsnitz/E. (between Hohndorf and Gersdorf), which shows a significantly slower uplift movement since 2016 and in Figure 10 the PS point P2 in the center of the city of Oelsnitz/E. is presented, which shows a later beginning (since 2016) uplift process. Of course, there are also PS points that show an approximately linear movement behavior over the entire period, but this group is not representative for the entire study area. Therefore, the chosen approach of assuming a piecewise linear movement behavior appears to be the most suitable for mapping differences in the movement dynamic when modeling the phenomenon.

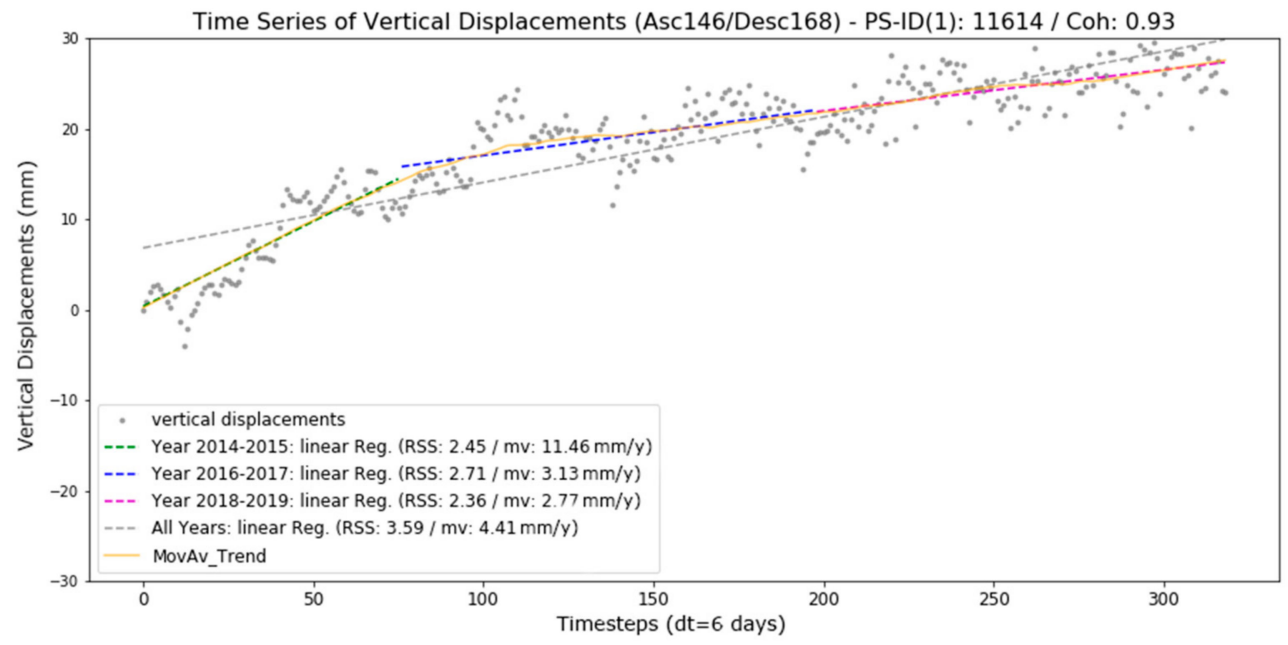

Figure 9. Time series of vertical ground movement $(\mathrm{mm})$ with derived movement trends for different time horizons for the persistent scatterers (PS) point (P1) northern of the city of Oelsnitz/E. (between Hohndorf and Gersdorf). 


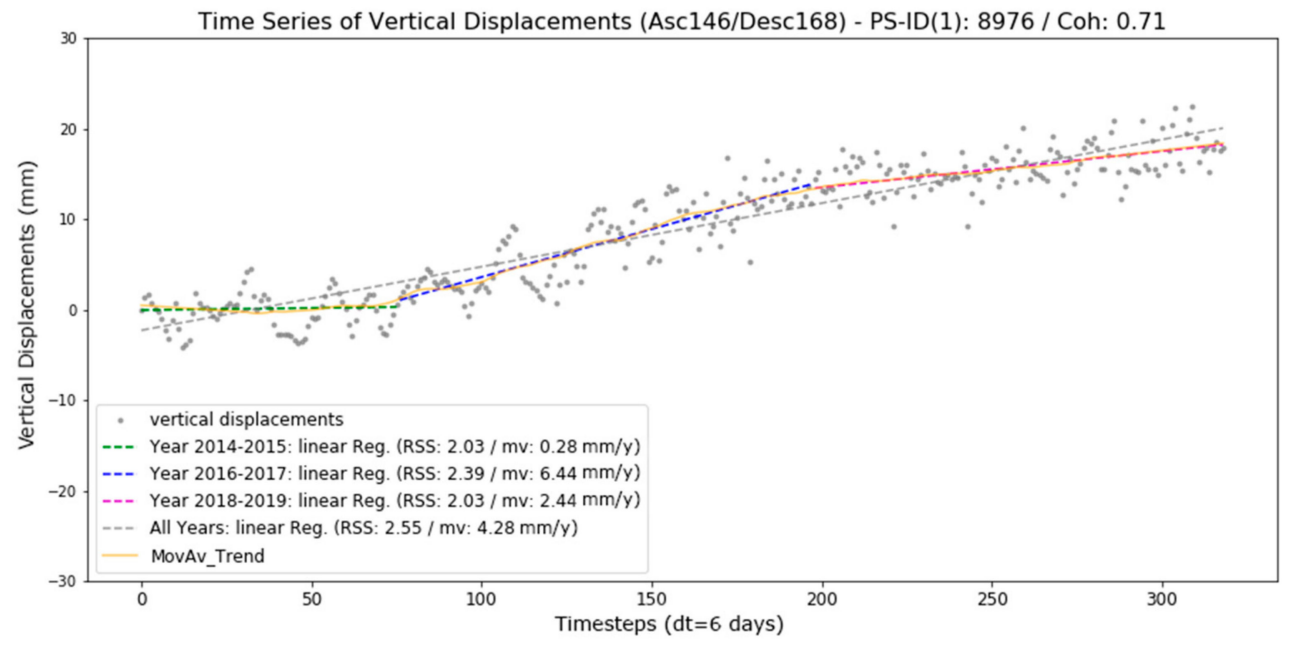

Figure 10. Time series of the vertical ground movement $(\mathrm{mm})$ with derived movement trends for different time horizons for the PS point (P2) in the center of the city of Oelsnitz/E.

For the time series of the ground movements in the horizontal (east-west) direction, no significant change in the movement behavior can be identified. For the vast majority of the PS points, an almost linear movement behavior is shown. Although it must be noted critically, that the order of magnitude of the movement trends determined were at the limit of detectability. Due to the very small amounts of horizontal movements in the east-west direction ( $\pm 1.5 \mathrm{~mm} / \mathrm{y})$ and the almost linear movement behavior, in opposite to the vertical time series, no derivation of movement trends was made for parts of the investigation period. For further considerations of the horizontal movements, the movement rate from the linear regression over the entire period $(10 / 2014-12 / 2019)$ was used. Figures 11 and 12 show two examples of time series of the horizontal east-west movement from the western (P3) and eastern (P4) flank of the uplift area. The location of the points $\mathrm{P} 3$ and P4 are shown in Figure 8.

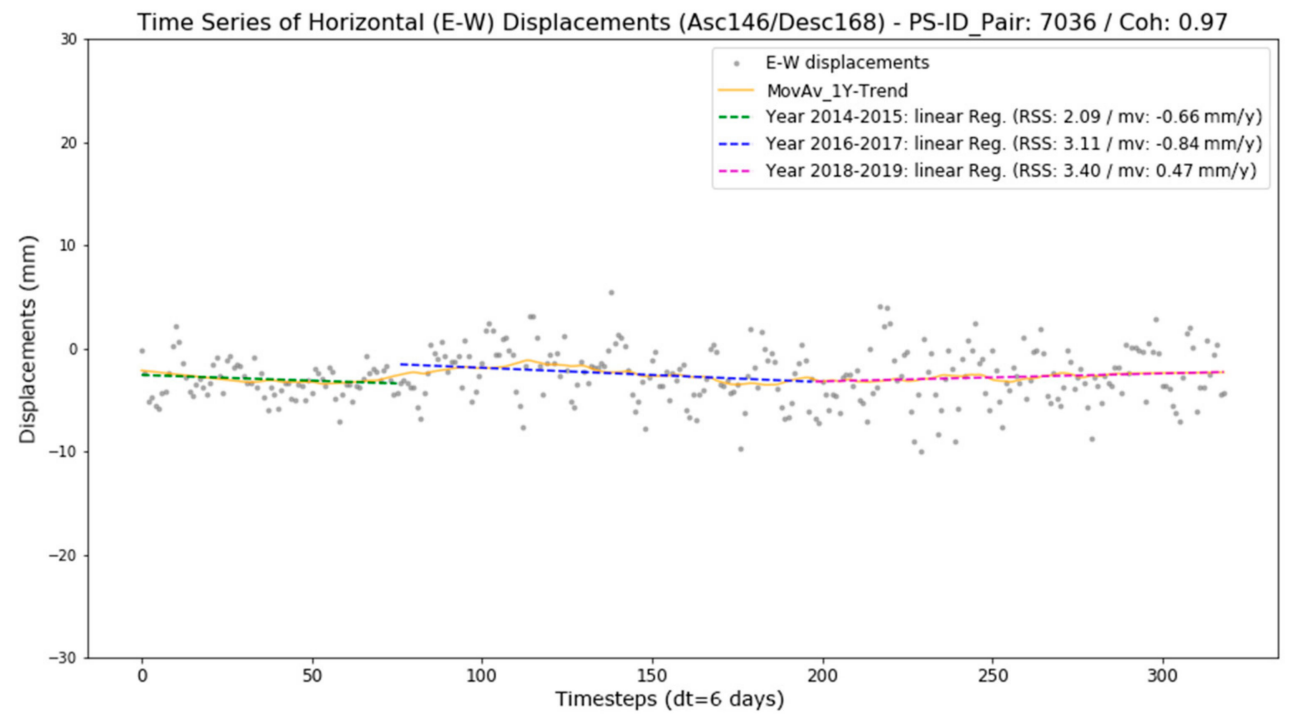

Figure 11. Time series of the horizontal ground movement (east-west) (mm) + derived movement trends for different time horizons for the PS point (P3) on the western flank of the uplift area. 


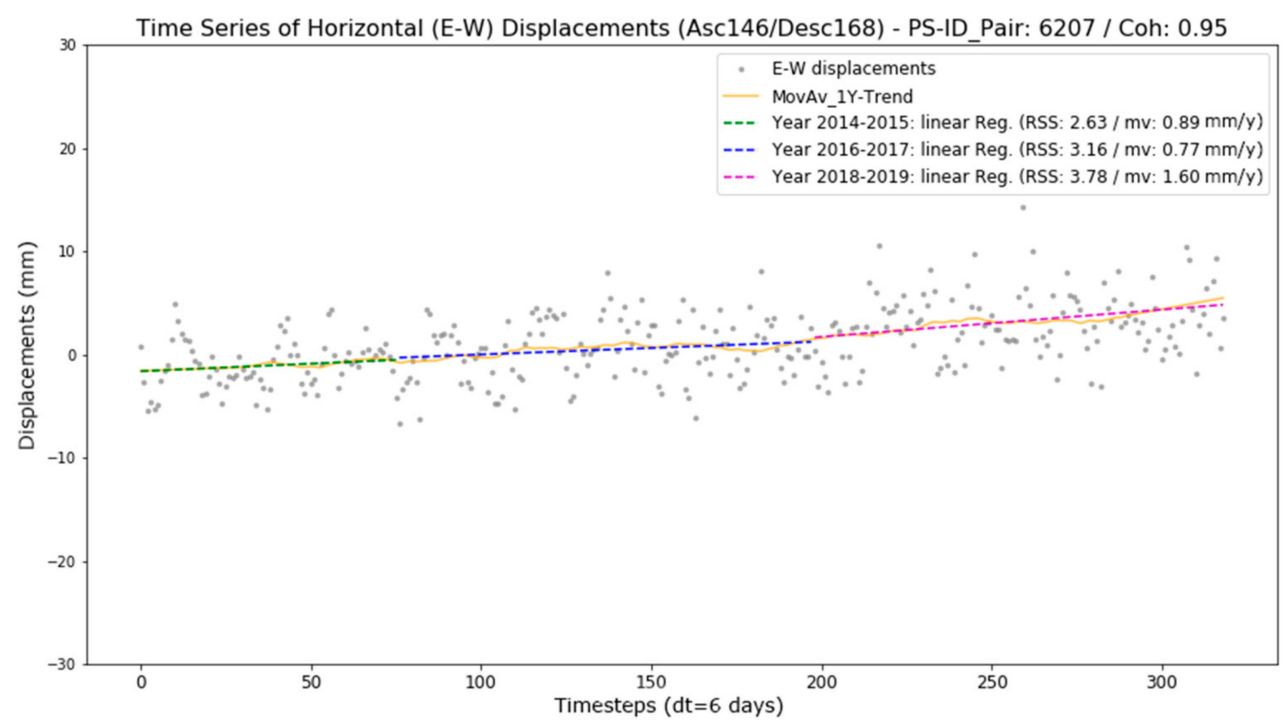

Figure 12. Time series of the horizontal ground movement (east-west) (mm) + derived movement trends for different time horizons for the PS point (P4) on the eastern flank of the uplift area.

Apart from the derivation of movement trends and movement rates, the PSI time series also offer the possibility to investigate seasonal effects of the movement dynamic. Being able to observe such seasonal effects is a clear advantage of the monitoring with radar interferometry compared to classic leveling with a significantly coarser time resolution. Figure 13 shows exemplary results for the PS point (P1) in the decomposition of the PSI time series into the usual components trend, seasonality and residual. For the PSI points in the investigation area, the seasonal influence in the time series of the vertical movement was recognized very clearly. You can see a clear contraction in the cooler months and an expansion in the summer months. The order of magnitude of this seasonal component averaged around $4-6 \mathrm{~mm}$ for the PS points in the study area. Similar observations could already be made in [33] when analyzing a carbonates underground mine. As recognized in [33], the knowledge about such seasonal cycles can be used for further investigations in the area, or in areas with similar geological conditions, or even for any correction on leveling data, if these were not always recorded at comparable times in the year.
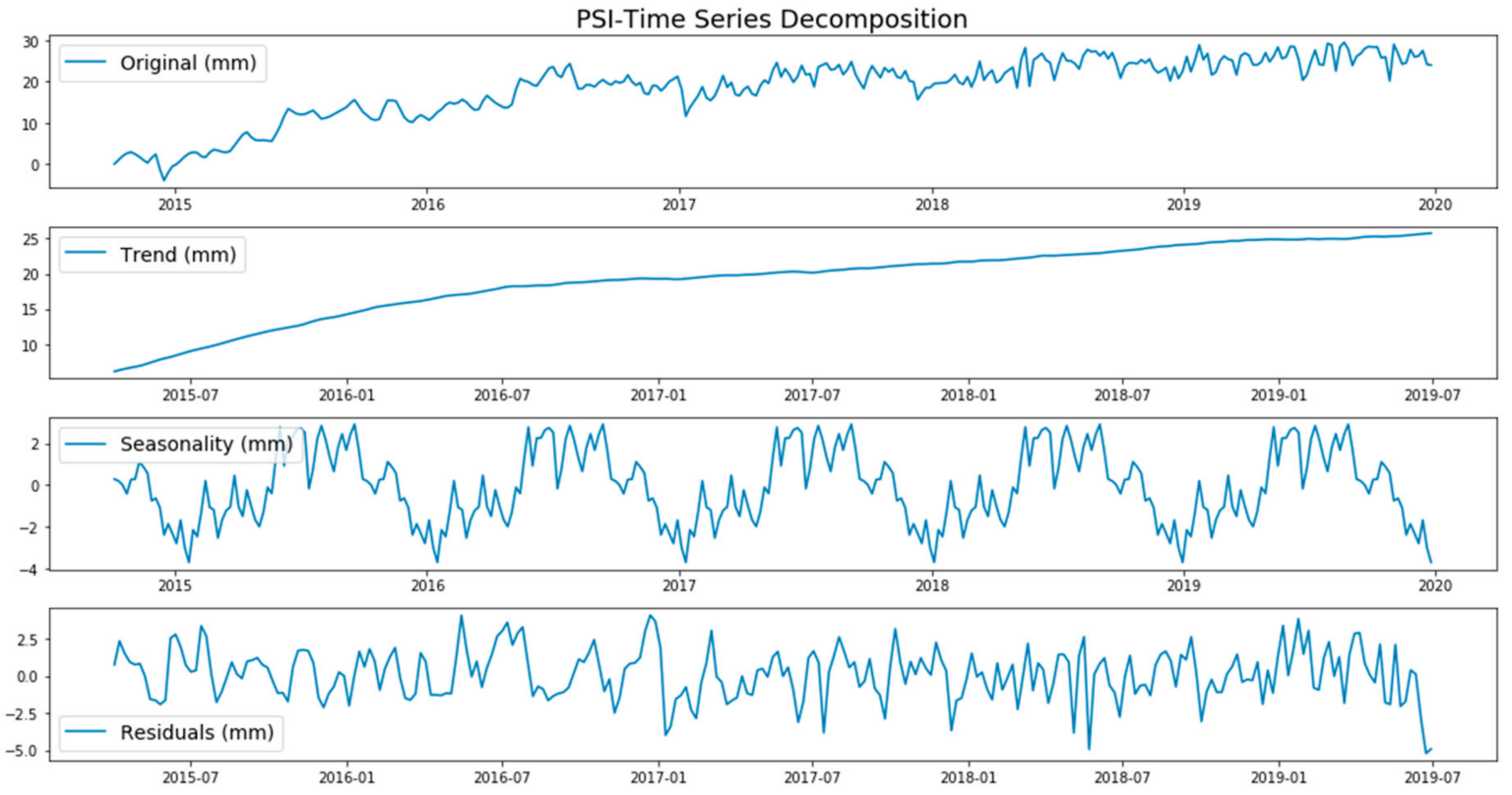

Figure 13. PSI time series decomposition for the PS point (P1). 


\subsection{Modeling the Ground Movements}

For the modeling of the movement rates in the Lugau/Oelsnitz mining area, a regular interpolation grid with a cell size of $2 \mathrm{~m} \times 2 \mathrm{~m}$ and an extent of $10 \mathrm{~km} \times 13 \mathrm{~km}$ was defined in the study area covering the uplift phenomenon. The data basis for the modeling of the movement rates for different observation periods was formed by a data set that was filtered or thinned out in terms of quality, i.e., coherence. A coherence value $\geq 0.95$ was set as the filter criterion. This strict filter criterion reduced the number of available PSI points, but this ensured the quality of the modeling results. A good spatial coverage of the study area was also guaranteed by the filtered data set. An ordinary Kriging interpolation with a linear model was used for the modeling. The results of modeling the vertical movement rate for the periods 2014/2015, 2016/2017 and 2018/2019 are shown in Figures 14-16. The filtered PSI point data set and the isolines from the kriging interpolation are shown in each case. The $50 \mathrm{~cm}$ subsidence line and a topographical map are also visualized for better orientation. In Figure 17, analogous to the previous figures, the result of modeling the horizontal movement rates in the east-west direction is shown. These movement rates were valid for the entire investigation period (2014-2019) due to the linear behavior.

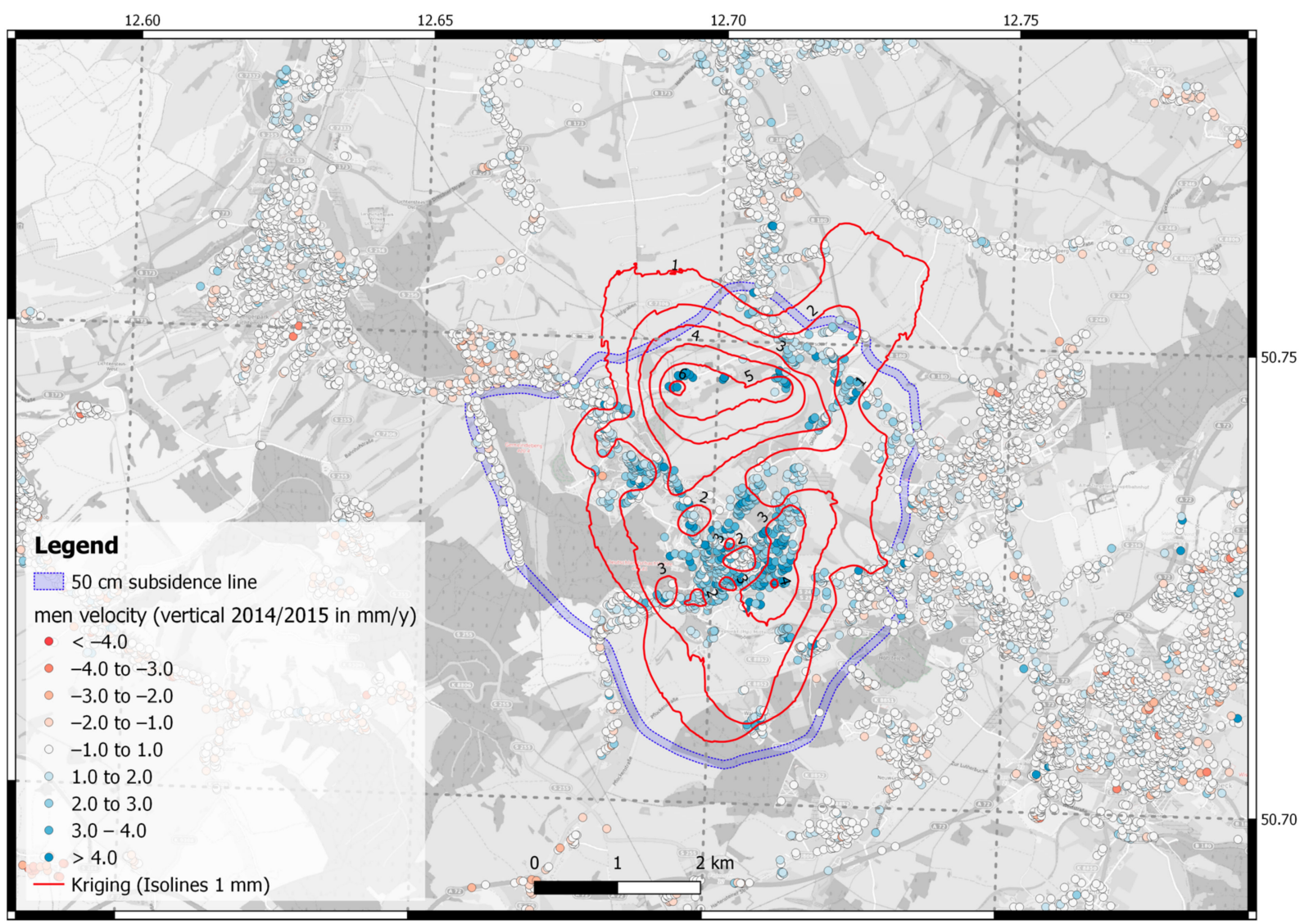

Figure 14. Modeling the vertical ground movement rate in the period 2014-2015 (C OpenStreetMap contributors).

The present results fit very well with the preliminary outcomes from previous radar interferometric evaluations $[11,34,35]$ in the study area. The analysis of the temporal course of the vertical ground movements based on the available modeling results shows a weakening of the uplift rates in the north of the city of Oelsnitz/E. from 2016/2017 and initially a shift and increase in ground movements towards the south-east. From the 2018/2019 period onwards, the uplift appeared in the south of the city of Oelsnitz/E. (near Waldesruh district) to be in decline again. 


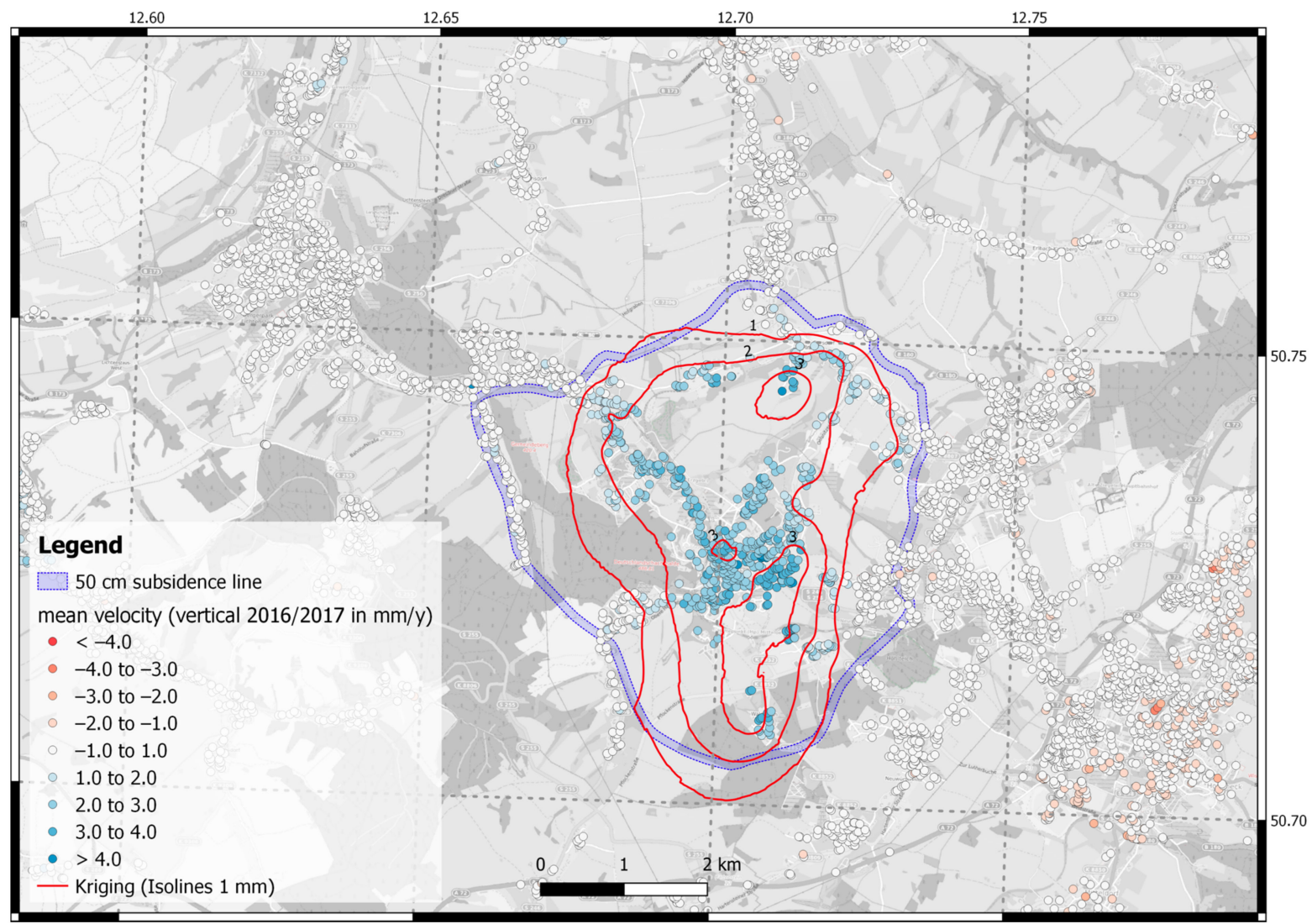

Figure 15. Modeling the vertical ground movement rate in the period 2016-2017 (@ OpenStreetMap contributors).

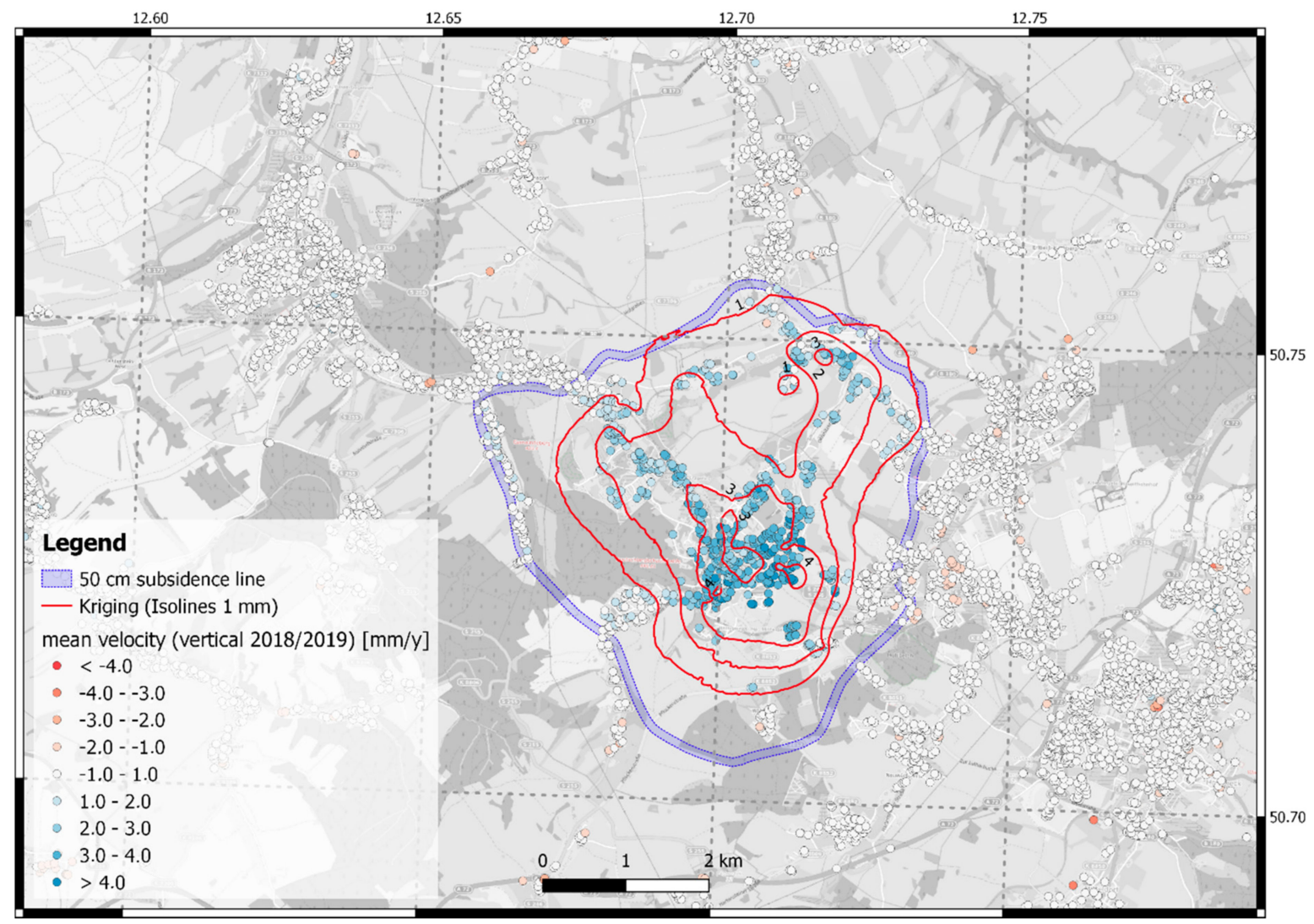

Figure 16. Modeling the vertical ground movement rate in the period 2018-2019 (C OpenStreetMap contributors). 


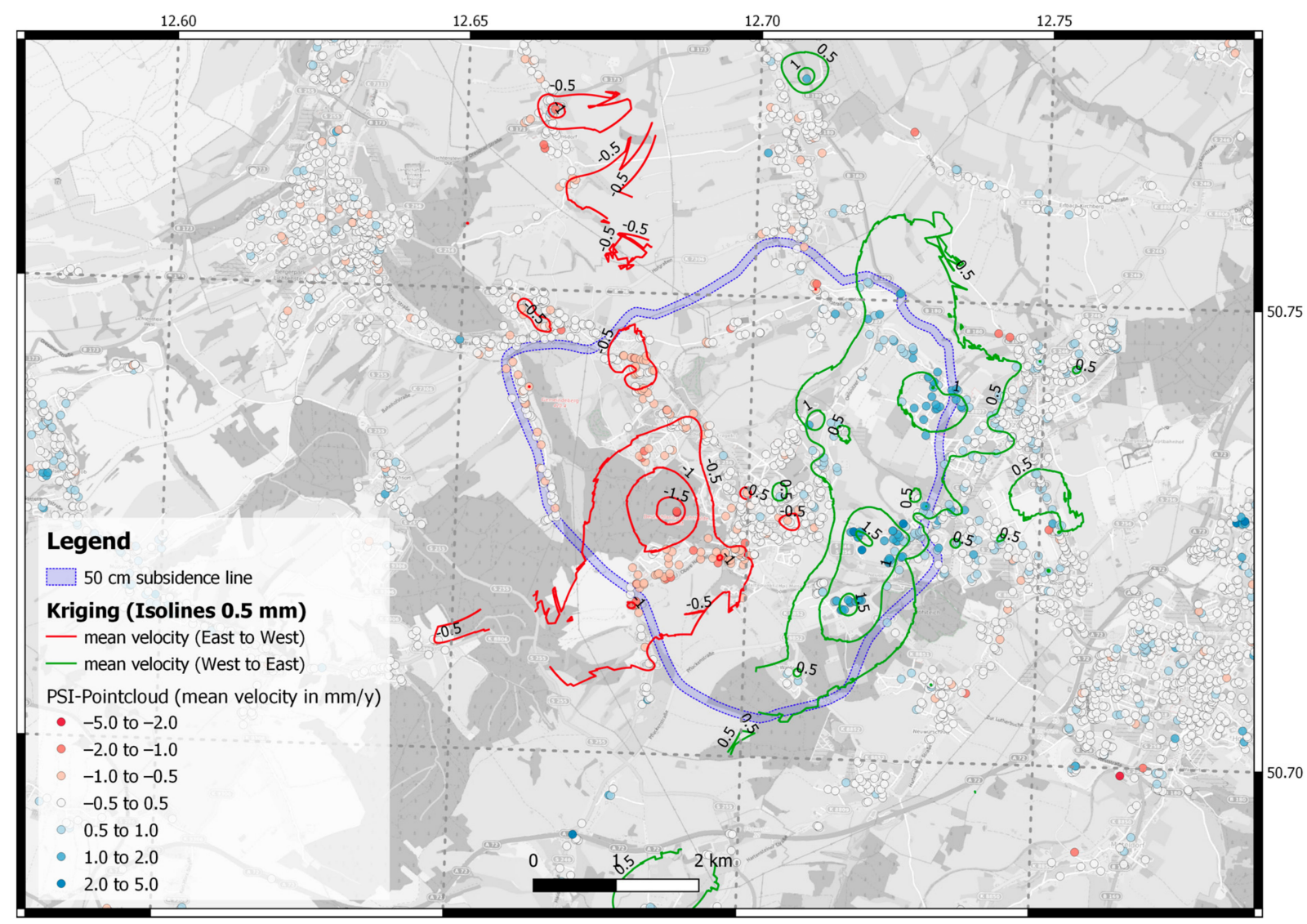

Figure 17. Modeling the horizontal (east-west) movement rate in the period 2014-2019 (@ OpenStreetMap contributors).

\section{Conclusions and Suggestions for Future Work}

The positive results of the carried-out radar interferometric evaluation showed that the methods used were very well suited to investigating mining and flooding-related subsidence and uplift of the Earth's surface in the former hard coal mining district of Lugau/Oelsnitz. Radar interferometry has been proven to be a suitable tool for costeffective long-term monitoring of subsidence and uplift in the post-mining phase of disused mining areas. The significantly greater spatial and temporal information density compared to conventional terrestrial measurement methods offered significantly more possibilities in the analysis of spatiotemporal phenomena of the Earth's surface.

In order to be able to monitor the ground movements caused by the mine water rise in the best possible way in the future, a monitoring concept was proposed, which provides for a continuation of the PSI evaluation of radar data from the Sentinel-1 satellites as an essential source of information. However, in order to connect the PSI point clouds with high accuracy to known measurement networks and to be able to punctual validate the results, the installation of corner reflectors is strongly recommended. Since the corner reflectors can of course only be used in a PSI evaluation once they have been installed in the field, they should be set up in the investigation area as soon as possible. In Figure 18, on the basis of the PSI point density and the dynamics of the ground movements in the past few years, potentially interesting areas (No. 1 to 6) for corresponding locations of corner reflectors are suggested. If the proposed configuration for monitoring the study area is fully implemented, it will be possible to completely dispense with the leveling in the future. 


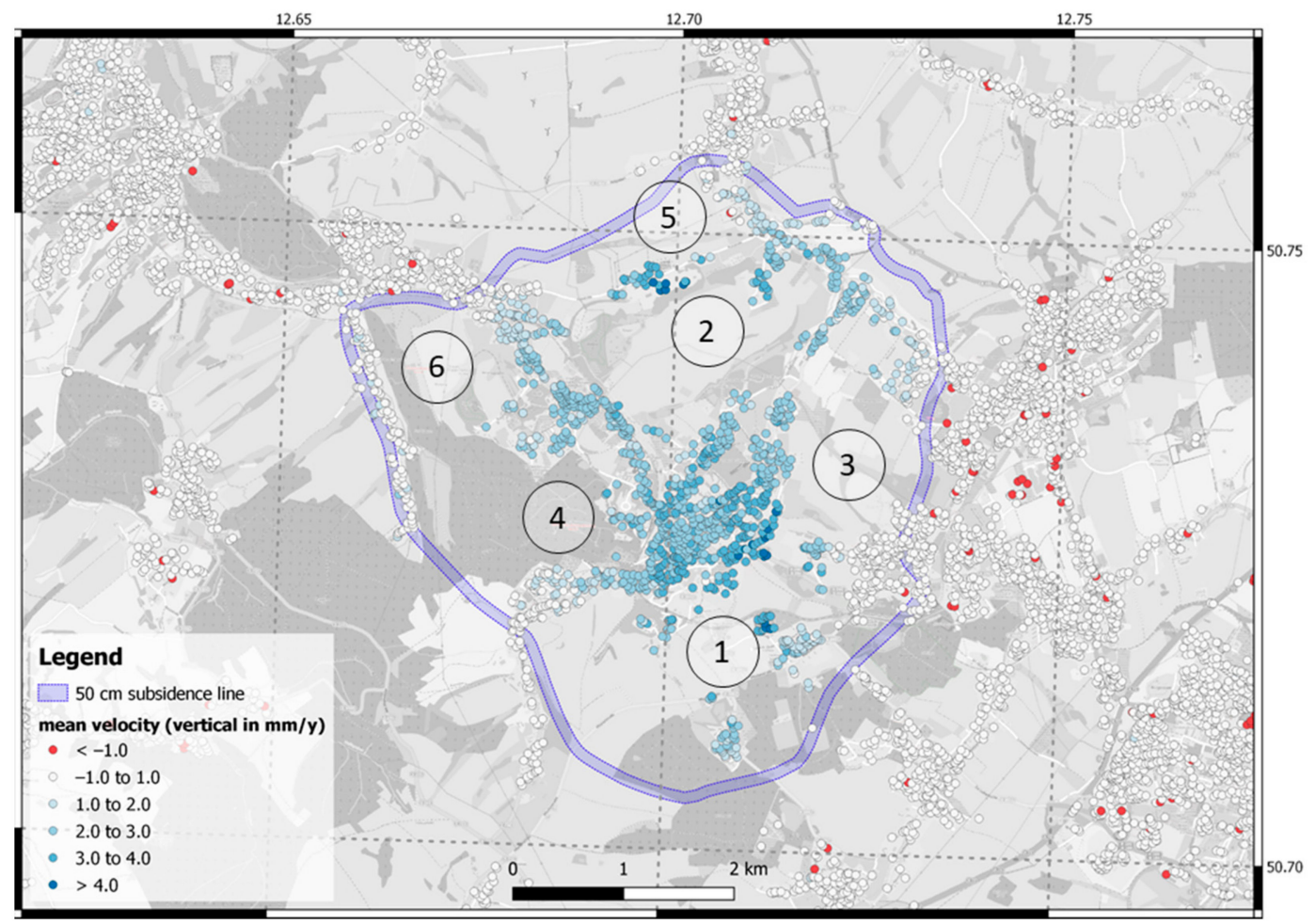

Figure 18. Proposal for theoretically suitable locations of corner reflectors in the study area (@ OpenStreetMap contributors).

For the future continuation of the PSI evaluation in the coming years, however, the entire extended period should not always be analyzed, since an ever-increasing expansion of the analyzed period caused the number of resulting PSI points to decrease due to temporal decorrelation effects. Therefore, in the context of future PSI evaluations, strategies for linking PSI time series from independent analyses of different time periods should also be examined and implemented accordingly. Not least for the integration and evaluation of corner reflectors that may have been installed in the meantime.

Funding: This research received no external funding.

Institutional Review Board Statement: Not applicable.

Informed Consent Statement: Not applicable.

Data Availability Statement: Publicly available Sentinel-1 datasets provided by the European Space Agency (Copernicus Open Access Hub) were analyzed in this study. For other data (leveling measurements) sharing is not applicable to this article.

Acknowledgments: The author would like to thank the local authorities of the city of Oelsnitz/E., the Saxon State Office for Environment, Agriculture and Geology (LfULG), the Saxon Mining Authority and the Beak Consultants $\mathrm{GmbH}$ for the good cooperation in context of the presented research in the past. Thanks also to all contributing researcher and developer referenced in this paper.

Conflicts of Interest: The authors declare no conflict of interest.

\section{References}

1. Salmi, E.F.; Malinowska, A.; Hejmanowski, R. Investigating the post-mining subsidence and the long-term stability of old mining excavations: Case of Cow Pasture Limestone Mine, West Midlands, UK. Bull. Int. Assoc. Eng. Geol. 2019, 79, 225-242. [CrossRef]

2. Sopata, P.; Stoch, T.; Wójcik, A.; Mrocheń, D. Land Surface Subsidence Due to Mining-Induced Tremors in the Upper Silesian Coal Basin (Poland)—Case Study. Remote Sens. 2020, 12, 3923. [CrossRef]

3. Ilieva, M.; Polanin, P.; Borkowski, A.; Gruchlik, P.; Smolak, K.; Kowalski, A.; Rohm, W. Mining Deformation Life Cycle in the Light of InSAR and Deformation Models. Remote Sens. 2019, 11, 745. [CrossRef]

4. Kratzsch, H. Bergschadenkunde (Mining Subsidence Engineering), 3rd ed.; Springer: Berlin/Heidelberg, Germany, 1974. 
5. $\quad$ Berger, H.-J.; Steinborn, H.; Goerne, S.; Junghans, C. Stratigraphie und tektonik im steinkohlerevier Lugau/Oelsnitz (Stratigraphy and tectonics in the coal mine area Lugau/Oelsnitz). In Geologie und Bergbaufolgen im Steinkohlerevier Lugau/Oelsnitz-Geoprofil 13; Saxon State Office for Environment, Agriculture and Geology (LfULG): Dresden, Germany, 2010; pp. 15-44.

6. Loebel, K.-H.; Doehner, S. Bergbaubedingte Senkungen und Hebungen in Oelsnitz/E. (Mining-related subsidence and uplift in Oelsnitz/E). In Geologie und Bergbaufolgen im Steinkohlerevier Lugau/Oelsnitz-Geoprofil 13; Saxon State Office for Environment, Agriculture and Geology (LfULG): Dresden, Germany, 2010; pp. 55-70.

7. Beyer, C. Bergschadenkundliche Analyse (Mining Damage Analysis) "Lugau/Oelsnitz"; Unpublished Report; Archiv Saechsisches Oberbergamt: Freiberg, Germany, 1974.

8. Felix, M.; Berger, H.-J. Das Grubenwasseranstiegsmodell im Steinkohlenrevier Lugau/Oelsnitz (The mine water rise model in the coal mining area Lugau/Oelsnitz). In Geologie und Bergbaufolgen im Steinkohlerevier Lugau/Oelsnitz-Geoprofil 13; Saxon State Office for Environment, Agriculture and Geology (LfULG): Dresden, Germany, 2010; pp. 7-14.

9. Abraham, T. Hydrochemische und Isotopenhydrogeologische Besonderheiten der Flutungswässer ehemaliger Steinkohlengruben in Oelsnitz/E. und Gersdorf (Hydrochemical and Isotope Hydrogeological Peculiarities of the Flood Waters of Former Coal Mines in Oelsnitz/E. and Gersdorf). In Proceedings of the 10th Mining Conference, Zwickau, Germany, 24 September 2018.

10. Hädecke, S.; Ussath, M.; Jahns, C.; Hübschmann, M. Visualisierung und Prognostizierung von Bergbaufolgen am Beispiel des Grubenwasseranstiegs im ehemaligen Steinkohlenrevier Lugau/Oelsnitz (Sachsen) (Visualization and Forecasting of Mining Consequences Using the Example of Mine Water Rise in the Former Coal Mining Area Lugau/Oelsnitz (Saxony)). In Proceedings of the Bergbau, Energie und Rohstoffe, Bochum, Germany, 11-13 September 2019; Papierfliege: Clausthal-Zellerfeld, Germany, 2019; pp. 164-171, ISBN 978-3-86948-692-5.

11. John, A.; Löbel, K.H. Bewertung von Unsicherheiten radarinterferometrisch detektierter vertikaler Bodenbewegungen in Folge des Grubenwasseranstiegs im ehemaligen Steinkohlenrevier Oelsnitz/E., (Assessment of the Uncertainties of Vertical Ground Movements Detected by Radar Interferometry as a Result of Mine Water Rise in the Former Coal Mine in Oelsnitz/E.). In Tagungsband, Geokinematischer Tag; Tagungsband-Wagner Digitaldruck und Medien GmbH, S: Freiberg, Germany, 2018; pp. 136-160. ISBN 978-3-938390-23-8.

12. Skolnik, M.I. Radar Handbook, 3rd ed.; McGraw-Hill Education: New York, NY, USA, 2008.

13. Skolnik, M.I. Introduction to Radar Systems, 2nd ed.; McGraw-Hill Kogakusha Ltd.: New York, NY, USA, 2008.

14. Hanssen, R. Radar Interferometry-Data Interpretation and Error Analysis; Kluwer Academic Publishers: Dordrecht, Germany, 2001.

15. Ferretti, A.; Prati, C.; Rocca, F. Permanent scatterers in sar interferometry. IEEE Trans. Geosci. Remote Sens. 2001, 39, 8-20. [CrossRef]

16. Werner, C.; Wegmuller, U.; Strozzi, T.; Wiesmann, A. Interferometric point target analysis for deformation mapping. In Proceedings of the 2003 IGARSS IEEE International Geoscience and Remote Sensing Symposium, Melbourne, Australia, 21-25 July 2003; Volume 7, pp. 4362-4364.

17. Hunter, J.D. Matplotlib: A 2D graphics environment. Comput. Sci. Eng. 2007, 9, 90-95. [CrossRef]

18. Walter, D. Systematische Einflüsse Digitaler Höhenmodelle auf die Qualität Radarinterferometrischer Bodenbewegungsmessungen (Systematic Influences of Digital Elevation Models on the Quality of Radar Interferometric Ground Motion Measurements). Ph.D. Thesis, TU Clausthal, Clausthal-Zellerfeld, Germany, 2012. Available online: http:/ /d-nb.info/1024299473/34 (accessed on 1 February 2021).

19. Crosetto, M.; Monserrat, O.; Cuevas-González, M.; Devanthéry, N.; Crippa, B. Persistent scatterer interferometry: A review. Theme issue "State-of-the-art in photogrammetry, remote sensing and spatial information science". ISPRS J. Photogramm. Remote Sens. 2016, 115, 78-89. [CrossRef]

20. Hooper, A.; Zebker, H.; Segall, P.; Kampes, B. A new method for measuring deformation on volcanoes and other natural terrains using InSAR persistent scatterers. Geophys. Res. Lett. 2004, 31, L23611. [CrossRef]

21. Hooper, A. A multi-temporal InSAR method incorporating both persistent scatterer and small baseline approaches. Geophys. Res. Lett. 2008, 35, L16302. [CrossRef]

22. Hooper, A.; Zebker, H.A. Phase unwrapping in three dimensions with application to InSAR time series. J. Opt. Soc. Am. A 2007, 24, 2737-2747. [CrossRef] [PubMed]

23. Michel, R.; Avouac, J.P.; Taboury, J. Measuring ground displacements from SAR amplitude images: Application to the Landers Earthquake. Geophys. Res. Lett. 1999, 26, 875-878. [CrossRef]

24. Bechor, N.B.D.; Zebker, H.A. Measuring two-dimensional movements using a single InSAR pair. Geophys. Res. Lett. 2006, 33, L16311. [CrossRef]

25. Mastro, P.; Serio, C.; Masiello, G.; Pepe, A. The multiple aperture SAR interferometry (MAI) Technique for the detection of large ground displacement dynamics: An overview. Remote Sens. 2020, 12, 1189. [CrossRef]

26. Dheenathayalan, P.; Small, D.; Schubert, A.; Hanssen, R.F. High-precision positioning of radar scatterers. J. Geod. 2016, 90, 403-422. [CrossRef]

27. Schubert, A.A.; Small, D.; Miranda, N.; Geudtner, D.; Meier, E. Sentinel-1A product geolocation accuracy: Commissioning phase results. Remote Sens. 2015, 7, 9431-9449. [CrossRef]

28. Busch, W.; Walter, D.; Coldewey, W.G.; Hejmanowski, R. Bergwerk Lohberg/Osterfeld der RAG AG. Analyse von Senkungserscheinungen Außerhalb des Prognostizierten Einwirkungsbereiches (Analysis of Subsidence Phenomena outside the Forecast Area of Impact). Gutachten im Auftrag der Bezirksregierung Arnsberg; Institut für Geotechnik und Markscheidewesen: Clausthal-Zellerfeld, Germany, 2017. 
29. Knospe, S.; Niemeier, W. Die Anwendung der satellitengestützten Radarinterferometrie zur großräumigen Erfassung von Höhenänderungen (The Use of Satellite-Based Radar Interferometry for Large-Scale Detection of Changes in Altitude). In Proceedings of the Tagungsband Geomonitoring 2011, Clausthal-Zellerfeld, Germany, 3-4 March 2011; Eigenverlag der TU Clausthal. ISBN 3-938924-11-X.

30. Foumelis, M.; Blasco, J.M.; Desnos, Y.-D.; Engdahl, M.; Fernandez, D.; Veci, L.; Lu, J.; Wong, C. ESA SNAP-StaMPS Integrated processing for Sentinel-1 Persistent Scatterer Interferometry. IEEE Int. Geosci. Remote Sens. Sympos. IGARSS 2018. [CrossRef]

31. Groot, J.; Otten, M. SAR Imaging of Corner Reflectors Larger Than the Spatial Resolution. IEEE Trans. Geosci. Remote Sens. 1994, 32, 721-724. [CrossRef]

32. Garthwaite, M. On the Design of Radar Corner Reflectors for Deformation Monitoring in Multi- Frequency InSAR. Remote Sens. 2017, 9, 648. [CrossRef]

33. Restrepo, D.A. Land Subsidence Monitoring for Small Underground Mines on Reclamation and Post Mining Stages Using InSAR-Case Study Carbonates Underground Mine Lengefeld. Master's Thesis, Institute for Mine Surveying and Geodesy, Freiberg, Germany, 2020.

34. John, A.; Löbel, K.-H. Copernicus-Satellitendaten für das Monitoring von vertikalen Bodenbewegungen durch Grubenwasseranstieg im ehemaligen Steinkohlerevier Oelsnitz/E., (Copernicus Satellite Data for the Monitoring of Vertical Ground Movements Caused by the Rise in Mine Water in the Former Coal Mining Area of Oelsnitz/E.) Altbergbaukolloquium, Wieliczka 2018; Tagungsband-Wagner Digitaldruck und Medien GmbH, S: Freiberg, Germany, 2008; pp. 101-119. ISBN 978-3-938390-22-1.

35. John, A. Untersuchungen zum Monitoring von Bodenbewegungen in Folge des Grubenwasser-anstiegs im ehemaligen Steinkohlerevier Oelsnitz/Erzgebirge mittels Radarinterferometrie, (Investigations to the Monitoring of Ground Movements as a result of the Rise in Mine Water in the Former Coal Mining Area Oelsnitz/E. Using Radar Interferometry). In Proceedings of the Altbergbaukolloquium, Leoben, Germany, 7-9 November 2019; Tagungsband-Wagner Digitaldruck und Medien GmbH, S: Freiberg, Germany, 2019; pp. 127-142, ISBN 978-3-938390-24-5. 